\title{
Polyphenols: A concise overview on the chemistry, occurrence, and human health
}

\author{
Alessandra Durazzo $^{1}$ (D) | Massimo Lucarini $^{1}$ (D) | Eliana B. Souto ${ }^{2,3}$ (D) | Carla Cicala ${ }^{4}$ (D) । \\ Elisabetta Caiazzo ${ }^{\text {(D) । Angelo A. Izzo }}{ }^{4}$ (D) | Ettore Novellino ${ }^{4}$ (D) | Antonello Santini ${ }^{4}$ (D)
}

${ }^{1}$ CREA - Research Centre for Food and Nutrition, Rome, Italy

${ }^{2}$ Faculty of Pharmacy of University of Coimbra Azinhaga de Santa Comba, Coimbra, Portugal

${ }^{3}$ CEB-Centre of Biological Engineering, University of Minho, Braga, Portugal

${ }^{4}$ Department of Pharmacy, University of Napoli Federico II, Napoli, Italy

\section{Correspondence}

Antonello Santini, Department of Pharmacy, University of Napoli Federico II, Via D. Montesano 49, Napoli 80131, Italy.

Email: asantini@unina.it
This review gives an updated picture of each class of phenolic compounds and their properties. The most common classification implies the subdivision of phenolics in two main groups: flavonoids (e.g., anthocyanins, flavanols, flavanones, flavonols, flavonones, and isoflavones) and non-flavonoids (e.g., phenolic acids, xanthones, stilbens, lignans, and tannins) polyphenols. The great interest in polyphenols is associated with their high potential application for food preservation and for therapeutic beneficial use. The relationship between polyphenol intake and human health has been exploited with special reference to cardiovascular diseases, hypertension, diabetes, metabolic syndrome, obesity, and cancer. The use of current existing databases of bioactive compounds including polyphenols is described as key tools for human health research.

\section{KEYWORDS}

anthocyanins, cancer, flavonoids, Food Composition Databases, metabolic syndrome, phytoestrogens, polyphenol intake, proanthocyanidins, cardiovascular disease

\section{1 | INTRODUCTION}

Bioactive compounds are defined as compounds that occur in nature and are part of the food chain. They have the ability to interact with one or more compounds of the living tissue, by showing an effect on human health (Biesalski et al., 2009). The infinite combinations of functional groups, that is, hydroxyls, alcohols, aldehydes, alkyls, benzyl rings, and steroids, lead to a great diversity of plant compounds, each one with peculiar characteristics (Roessner \& Beckles, 2009).

Within nutraceuticals (Andrew \& Izzo, 2017; Daliu, Santini, \& Novellino, 2019; Durazzo \& Lucarini, 2018; Santini et al., 2018; Santini \& Novellino, 2014; Santini \& Novellino, 2018; Santini, Tenore, \& Novellino, 2017), more than 8,000 different phenolics are identified in the plant kingdom and represent one of most numerous and widely distributed class of plant secondary metabolites (Cheynier, Comte, Davies, Lattanzio, \& Martens, 2013; Kabera, Semana, Mussa, \& He, 2014; Santini, Novellino, Armini, \& Ritieni, 2013). Several outstanding reviews on polyphenols have been recently published (Amiot, Riva, \& Vinet, 2016; Bernatoniene \& Kopustinskiene, 2018; Białecka-
Florjańczyk, Fabiszewska, \& Zieniuk, 2018; Clifford, Jaganath, Ludwig, \& Crozier, 2017; Costa et al., 2017; Durazzo et al., 2018; Pervaiz, Songtao, Faghihi, Haider, \& Fang, 2017; Roche et al., 2017; Xiao, Zhang, Tong, \& Shi, 2018; H. Zhang \& Tsao, 2016; Zhao et al., 2017), and the reader is referred to them for a more in-depth information. Here, we provide a concise introductory guide for the beginners in order to assist them in their initial entry into the chemistry and pharmacology of polyphenols. Specifically, we provide a concise overview on the chemistry and occurrence of the main classes of polyphenolic compounds as well as on the current evidence supporting (or not) an association between polyphenolic intake and the incidence of human chronic disease, with a special focus on cardiovascular diseases, metabolic syndrome (MetS), and cancer.

\section{I PHENOLIC COMPOUNDS}

Phenolics are own defined as compounds that possess an aromatic ring with at least one hydroxyl group, and their structure can vary 
from simple molecule to complex polymer with high molecular weight (El Gharras, 2009). There is discordance concerning the way to classify them. The most adopted classification implies the subdivision of phenolics in two main groups: flavonoids and non-flavonoid polyphenols, and this classification has been commonly used in the literature (de la Rosa, Alvarez-Parrilla, \& Gonzalez-Aguilar, 2010; Kabera et al., 2014).

\section{1 | Phenolic acids-Hydroxycinnamic and hydroxybenzoic acids}

Phenolic acids are non-flavonoid polyphenolic compounds present in foodstuffs and are characterized by a carboxyl group linked to benzene ring (Lafay \& Gil-Izquierdo, 2008). They are derived from two main phenolic compounds, benzoic and cinnamic acids. Examples of hydroxybenzoic derivatives are gallic, p-hydroxybenzoic, vanillic, and syringic acids, whereas caffeic, ferulic, sinapic, and p-coumaric acids belong to hydroxycinnamic acids (Amarowicz et al., 2009; Proestos, Koutelidakis, Kapsokefalou, \& Komaitis, 2011). It is worth mentioning the review of Khadem \& Marles (2010) that remarked how the wide diversity of naturally occurring phenolic acids, at least 30 hydroxyand polyhydroxybenzoic acids with biological activity, have been reported in the last 10 years. Recently, Roche et al. (2017) reported representative literature on the phytonutrients category of phenolic acids, with attention to the most prevalent ones, that is, gallic acid, tannic acid, and capsacin. For example, ellagic acid, abundant in cranberries, strawberries, blueberries, and blackberries, has been shown to decrease blood pressure and high blood cholesterol, to exert antiinflammatory properties and even to reduce skin wrinkles from radiation. Another example is gallic acid, which can be found in tea, mango, rhubarb, and soy and which is known mainly for its antioxidant effect (Roche et al., 2017).

Fruits and vegetables are characterized mainly by the presence of free phenolic acids, whereas grains and derivatives by bound phenolic acids (Chandrasekara \& Shahidi, 2010; D'Evoli et al., 2016; Dueñas et al., 2016; Stuper-Szablewska \& Perkowski, 2017).

The hydroxycinnamic (Alam et al., 2016; El-Seedi et al., 2012) are present at high concentrations in many food products, including fruits (especially the red colored ones), vegetables, tea, cocoa, wine, tea leaves, coffee, and whole grains (El Gharras, 2009; El-Seedi et al., 2012; Santana-Gálvez, Cisneros-Zevallos, \& Jacobo-Velázquez, 2017). Hydroxycinnamates can exist as monomers, dimers, or as (a) bound forms as ester (with hydroxy acids, mono/disaccharides, and polymers); (b) as amides (conjugated with mono- or polyamines, amino acids, or peptides). As instance, p-coumaric acid (4hydroxycinnamic acid) (Pei, Ou, Huang, \& Ou, 2016) is a phenolic acid that has low toxicity in mice $\left(\operatorname{LD}_{50}=2,850 \mathrm{mg} \mathrm{kg}^{-1}\right.$ of body weight) and acts as a precursor of other phenolic compounds. It exists either in free or conjugated form in plants (Pei et al., 2016). Clifford et al. (2017) have reviewed nomenclature, quantification, characterisation by NMR and MS, biosynthesis, and role of chlorogenic acids and of acyl-quinic acids, with attention to coffee. Coffee is the major human dietary source worldwide of acylquinic acids. Levels of total caffeoylquinic acids (including 3-caffeoylquinic acid A, 4caffeoylquinic acid $A$, and 5-caffeoylquinic acid $A$ ) in espresso coffees purchased from 20 different coffee shops ranged from 24 to $423 \mathrm{mg}$ (Romano et al., 2014; Santini et al., 2011).

In addition to hydroxycinnamic acids, phenolic compounds with C6-C3 carbon skeletons, also known as phenylpropanoids, includes curcuminoids, coumarins, and chromones. The most widely studied among the curcuminoids is curcumin (Tsuda, 2018). Curcumin, which represents by alone a constituent (up to $~ 5 \%$ ) of the traditional olistic medicine, is known as turmeric (Nakmareong et al., 2011; Nelson et al., 2017). Curcumin exerts a number of pharmacological actions of potential therapeutic interest (Atkin, Katsiki, Derosa, Maffioli, \& Sahebkar, 2017; Kocaadam \& Şanlier, 2017; Mantzorou, Pavlidou, Vasios, Tsagalioti, \& Giaginis, 2018; Milani, Basirnejad, Shahbazi, \& Bolhassani, 2017; Shen, Jiang, Yang, Wang, \& Zhu, 2017; Soleimani, Sahebkar, \& Hosseinzadeh, 2018), and it is extensively marketed worldwide as a nutraceutical (Santini \& Novellino, 2017a). Starting from the first clinical trial published in The Lancet in 1937 (Oppenheimer, 1937), more than 1,200 clinical trials involving more than 6,000 subjects have been carried out, and many systematic reviews have been published (Kunnumakkara et al., 2017). A recent overview of systematic reviews identified 22 systematic reviews related to the clinical efficacy of curcumin-containing nutraceuticals that have been published (Pagano, Romano, Izzo, \& Borrelli, 2018). On the basis of such analysis, there is evidence that curcumin might be useful for a number of health conditions including skin diseases, arthritisrelated diseases, metabolic diseases and possibly-in a very preliminary fashion-depressive disorders, and ulcerative colitis (Pagano et al., 2018). Such collectively promising results should be interpreted with the due attention to the high risk of bias in many primary trials and to the low-moderate level of some analyses (Pagano et al., 2018).

Coumarin class of organic compounds consists of 1,2-benzopyrone ring system as a basic parent scaffold. Since the last few years, coumarins were synthesized in many of their derivative forms. On the other hand, coumarins are considered phytoalexins, because they are overaccumulated in plant tissues as a result of both pathogen attack and abiotic stresses. Their pharmacological properties are related to their substitution pattern (Venkata Sairam, Gurupadayya, Chandan, Nagesha, \& Vishwanathan, 2016). The prototype of this class of molecules is coumarin, found in cinnamom and other plant, which can cause liver toxicity in several species, and it is considered a nongenotoxic carcinogen (Abraham, Wöhrlin, Lindtner, Heinemeyer, \& Lampen, 2010). Coumarins are known for their anticoagulant effects. The observation of fatal hemorrhage in cattle eating mouldy sweet clover, as a result of impaired coagulation, led to the introduction in therapy of the anticoagulant drug dicoumarol, which is chemically related to warfarin (Andrew \& Izzo, 2017). A Norwegian study has recently shown that children eating oatmeal porridge several times a week sprinkled with cinnamon could have a coumarin intake greatly exceeding the tolerable daily intake (Fotland, Paulsen, Sanner, Alexander, \& Husøy, 2012). Similarly, adults drinking cinnamon-based 
tea and consuming cinnamon supplements also can exceed the tolerable daily intake (Fotland, Paulsen, Sanner,Alexander, \& Husøy, 2012).

Among coumarins, auraptene, known also as 7-geranyloxycoumarin, is a natural prenyloxycoumarin present in plants of Rutaceae and Apiaceae families. Several biological activities such as antioxidant, anti-inflammatory, antibacterial, antifungal, and antigenotoxic are attributed to this compound (Genovese \& Epifano, 2011).

Chromone is recognized as a privileged structure and a useful template for the design of novel compounds with potential pharmacological interest, particularly in the field of neurodegenerative, inflammatory, and infectious diseases as well as diabetes and cancer (Reis, Gaspar, Milhazes, \& Borges, 2017). The chromone moiety (1,4-benzopyrone), shown in Figure 1, is the essential component of pharmacophores of a large number of bioactive molecules (Vanguru, Merugu, Garimella, \& Laxminarayana, 2018). Khellin, found in the fruit of Amni visnaga, is a well-known chromone, formerly used as an antispasmodic drug. Efforts to find better drugs led to the chemical development and synthesis of sodium cromoglycate (Andrew \& Izzo, 2017). The great interest in phenolic acids is associated with their high potential for food preservation and for therapeutic application (Białecka-Florjańczyk et al., 2018). Biological studies on hydroxycinnamic acids have been focused on their possible beneficial effects in neurodegenerative diseases, due to their anti-inflammatory, antioxidant, and neuroprotective actions (Zhang, Zhang, Ho, \& Huang, 2019), as well as on endothelial functions, via attenuation of oxidative stress, improvement of nitric oxide bioavailability, and decrease of Eselectin, ICAM-1, and VCAM-1 expression (Fuentes \& Palomo, 2014). Accordingly, association between phenolic acids intake and reduced blood pressure and triglycerides has been reported in observational studies (Grosso et al., 2018).

Hydroxybenzoic acids are known mainly due to their antioxidant properties with a potential in chronic diseases. Epidemiological studies have revealed inverse association between hydroxybenozoic acids intake and the risk of cardiovascular diseases and obesity (Guo et al., 2017; Tresserra-Rimbau et al., 2014a; Tresserra-Rimbau et al., 2014b).

\section{2 | Flavonoids}

Flavonoids are classified into the following subclasses: anthocyanins, flavanols, flavanones, flavonols, flavonones, and isoflavones (Amarowicz et al., 2009; Kabera et al., 2014; Kumar \& Pandey, 2013). A wide range of pharmacological activities, including antioxidant, antibacterial, hepatoprotective, antinflammatory, and antihyperlipidemic effect, are attributed to flavonoids (Abenavoli et al., 2018; Azzini et al., 2016; Belwal, Nabavi, Nabavi, \& Habtemariam, 2017; D'Evoli<smiles>O=c1ccoc2ccccc12</smiles>

FIGURE 1 The backbone structure of chromone et al., 2013; Farhadi, Khameneh, Iranshahi, \& Iranshahy, 2018; Farhat, Drummond, \& Al-Dujaili, 2017; Iriti et al., 2017; Miccadei et al., 2008; Ninfali, Antonini, Frati, \& Scarpa, 2017; Rasouli, Mohammad-Bagher Hosseini-Ghazvini, \& Khodarahmi, 2018; Rees, Dodd, \& Spencer, 2018; Riccio et al., 2018; Tungmunnithum, Thongboonyou, Pholboon, \& Yangsabai, 2018). The term flavonoid generally indicates a phenol compound having a phenylbenzopyran chemical structure with a carbon skeleton of a C6-C3-C6 joined to a chroman ring (Pereira, Valentão, Pereira, \& Andrade, 2009). In most of the cases, three or more $-\mathrm{OH}$ groups are linked to their backbone structure (Zhang \& Tsao, 2016). Flavonoids can occur as aglycones or as conjugated to sugars and/or organic acids (Khoddami, Wilkes, \& Roberts, 2013; Kumar \& Pandey, 2013). Flavonoids derived from the aromatic amino acids, phenylalanine, and tyrosine are $\mathrm{C} 15$ compounds arranged in three rings (C6-C3-C6) (Vermerris \& Nicholson, 2008); the degree and pattern of hydroxylation, prenylation, alkalization, or glycosylation reactions modify the primary structure of the molecule (Khoddami et al., 2013). The substitution of chemical groups in the flavonoid structures is correlated to the corresponding biological and/or chemical properties and bioavailability (Cermak et al., 2009; Teng \& Chen, 2019).

\subsection{1 | Flavanones}

Figure 2 shows the chemical structures of molecules belonging to flavanones, that is, hesperetin, naringenin, and eriodictyol. The work of Brahmachari (2008) describes more than 160 naturally occurring flavanones that belong to 36 plant families. Flavanones are present in vegetables, that is, tomato, potato (Durazzo et al., 2010), spices, that is, rosemary and peppermint (Bajkacz \& Adamek, 2017), and particularly in fruits, that is, lemon, orange, strawberry, raspberry, and plum (W. Cao et al., 2015; Pavlović et al., 2013; Sablani et al., 2010). Khan, Huma, and Dangles (2014) showed that hesperetin (Figure 6a) and

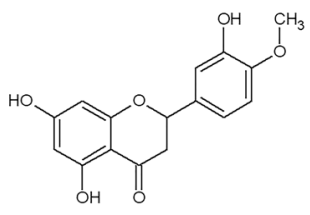

(a) hesperetin

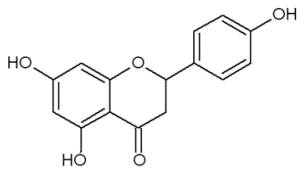

(b) naringenin

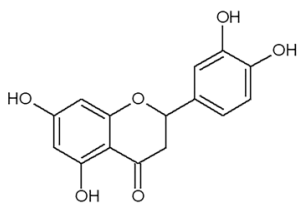

(c) eriodictyol

FIGURE 2 The chemical structures of (a) hesperetin, (b) naringenin, and (c) eriodictyol 
its derivatives are characteristic flavanones of sweet orange, tangelo, lemon, and lime, whereas naringenin (Figure 6b) and its derivatives are peculiar of grapefruit and sour orange. As instance, in citrus fruit, Barreca et al. (2017) reported quantities ranging from 180 to $740 \mathrm{mg} / \mathrm{L}$ of this compound. The recent study of Barbosa, Ruviaro, and Macedo (2018) is addressed on the comparison of different Brazilian citrus by-products as source of natural antioxidants, with focus on profile of flavanones: nine polyphenols were detected in the studied by-products, and hesperidin was the main compound found in the residues of citrus by-products after juice processing.

Flavanones intake has been associated with a reduced risk of diabetes and obesity (Adriouch et al., 2018; Tresserra-Rimbau et al., 2016). Naringenin, that is, the aglycone of naringin, is one of the best studied among the flavanones. It is mainly found in Citrus fruits, and a number of papers has highlighted its potential use in health conditions such as oxidative stress, inflammation, neurological disorders, and particularly cardiovascular/metabolic diseases (Salehi, Fokou, et al., 2019; Zeng, Jin, Zhang, Zhang, \& Liang, 2018). The daily mean intake of naringenin has been estimated to be $58.1 \mathrm{mg}$ (Ranka et al., 2008). Studies have been performed in hypercholesterolemic and overweight patients, with a dosage ranging between 600 and $800 \mu \mathrm{M} /$ day (Salehi, Fokou, et al., 2019). Naringenin decreases low density lipoproteins and triglycerides, increases high density lipoproteins, and inhibits glucose uptake. At a molecular level, it suppresses protein oxidation and macrophage inflammation, protects against intercellular adhesion molecule-1 (ICAM-1), inhibits leukotriene B4, monocyte adhesion, and foam cell formation (Orhan et al., 2015).

\subsection{2 | Flavonols}

Flavonols are reported to be present in onions, apples, persimmon, saffron, berries, broccoli, lettuce, tea, and red wine (Bataglion, da Silva, Eberlin, \& Koolen, 2015; Durazzo et al., 2014; Hoffmann-Ribani, Huber, \& Rodriguez-Amaya, 2009; Sultana \& Anwar, 2008; Valavanidis, Vlachogianni, Psomas, Zovoili, \& Siatis, 2009). A meta-analysis of epidemiologic studies has shown that the intake of flavonols may reduce the risk of type- 2 diabetes (Rienks, Barbaresko, Oluwagbemigun, Schmid, \& Nöthlings, 2018). Quercetin and kaempferol are the main representative molecules (Figure 3). A recent work has described the role of quercetin exploiting the previous published papers on the effect of quercetin (Hirpara, Aggarwal, Mukherjee, Joshi, \& Burman, 2009; L. Li, Zhang, \& Du, 2018; Miltonprabu et al., 2017; Oboh, Ademosun, \& Ogunsuyi, 2016; Rauf et al., 2018), and (Calderón-Montaño, Burgos-Morón, Pérez-Guerrero, \& López-Lázaro, 2011; A. Y. Chen \& Chen, 2013; Devi et al., 2015; Imran et al., 2019) against several chronic diseases.

Quercetin is mainly found in onions, apples, and berries; it has attracted researchers' attention for its activity against cancer prevention, chronic inflammation, and cardiovascular diseases. The estimated mean intakes of quercetin is $29.4 \mathrm{mg}$ per day (Ranka et al., 2008). Evidence suggests that quercetin negatively regulates key signaling pathways associated with life-threatening diseases, such as NF-KB, MAPK, PI3K-AKT, and mTOR. In addition, several patents have been<smiles>O=c1c(O)c(-c2ccc(O)c(O)c2)oc2cc(O)cc(O)c12</smiles>

(a) quercetin

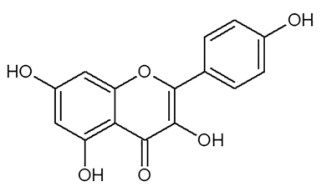

(b) kaempferol

FIGURE 3 The chemical structures of (a) quercetin and (b) kaempferol

recently reported on quercetin derivatives for wide therapeutic applications such as anticancer, antiaging, and as anti-inflammatory agent (Sharma, Kashyap, Sak, Tuli, \& Sharma, 2018). Quercetin is also marketed as a dietary supplement, and it is suggested to be assumed a dose up to $1,000 \mathrm{mg} /$ daily, an amount that exceeds the usual dietary intake levels (Andres et al., 2018). A recent meta-analysis of placebocontrolled randomized controlled trials showed a statistically significant effect of quercetin supplementation in the reduction of blood pressure, possibly at a dose higher than $500 \mathrm{mg} /$ day (Serban et al., 2016). A further meta-analysis of RCTs did not suggest any clinically relevant effect of quercetin supplementation on plasma lipids, apart from a significant reduction of triglycerides at doses above $50 \mathrm{mg} /$ day (Sahebkar, 2017). Finally, there is clinical evidence that quercetin provides benefits in human endurance exercise capacity and endurance exercise performance (Kressler, Millard-Stafford, \& Warren, 2011). The antioxidant and anti-inflammatory actions of quercetin (Chen, Jiang, Wu, \& Fang, 2016) may play a role in such clinical effect. Kaempferol is a natural flavonol present in different edible plants (e.g., tea, broccoli, cabbage, kale, beans, endive, leek, tomato, strawberries, and grapes). It has been described to possess antiinflammatory, anticancer, and notably cardiovascular protective properties (Devi et al., 2015; Rajendran et al., 2014). A prospective American study aiming at investigating the effect of flavonols and flavones on coronary heart disease risk showed protective effect in women associated with the highest kaempferol intake. The lower risk associated with kaempferol intake was probably due to broccoli consumption (Lin, Gong, Song, \& Cui, 2017). Similarly, kaempferol intake has been associated to the reduction of acute coronary syndrome (Rienks, Barbaresko, \& Nöthlings, 2017).

\subsection{3 | Flavanols}

Epicatechin, and catechins belong to subgroup of monomeric flavanols. The backbone structure of this catechins subclass is shown in Figure 4. The name catechin derived from the term catechu, the extract of Acacia catechu L. (Braicu, Ladomery, Chedea, Irimie, \& Berindan-Neagoe, 2013). The chemical structure is constitued by a 


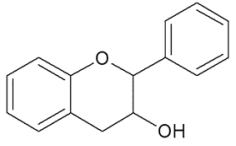

FIGURE 4 The structure backbone of catechins subclass

3,3',4,5,7-pentahydroxyflavone with two steric forms of (+)-catechin and its enantiomer (Bernatoniene \& Kopustinskiene, 2018). Flavanols can form gallic acid conjugates such as epicatechin gallate, epigallocatechin, and epigallocatechin gallate (Braicu et al., 2013; Rosen, 2012).

Catechins are major polyphenols in tea and have been related to the health beneficial health effects of tea (Annunziata et al., 2018; Zhang et al., 2019; Zhang, Tang, \& Row, 2014). Epigallocatechin-3-gallate (EGCG) is abundant in tea (Lambert et al., 2003), whose consumption has been correlated with a low incidence of chronic cardiovascular disease and cancer (Peluso \& Serafini, 2017). Recently, a unique O-methylated catechin, namely, the (-)-epigallocatechin 3-O-(3-O-methyl) gallate (EGCG3Me), has been identified in green and oolong tea varieties (Zhang et al., 2019). Cocoabased products, that is, chocolate, are rich catechin and epicatechin (Kofink, Papagiannopoulos, \& Galensa, 2007; Rodríguez-Carrasco, Gaspari, Graziani, Santini, \& Ritieni, 2018).

Other sources are fruits, such as grapes and blackberries, apples, or nuts like beans, almond, pistachos, and red wine (Bhagwat, Haytowitz, \& Holden, 2014; Cassino, Tsolakis, Bonello, Gianotti, \& Osella, 2019; Gadkari \& Balaraman, 2015; Harnly et al., 2006; Martinez et al., 2016).

Cocoa and chocolate flavonols have attracted clinical attention for the prevention of cardiovascular and metabolic diseases. A systematic review and meta-analysis of RCTs, which included 19 RCTs for a total of 1,131 participants showed that cocoa flavanol intake had favorable effects on select cardiometabolic biomarkers among adults (Lin et al., 2016). A meta-analysis of ten RCTs comprising 297 individuals showed the blood pressure-lowering ability of flavanol-rich cocoa products (Desch et al., 2010). Such results have been confirmed by a more recent Cochrane review, which, on the basis of 35 randomized clinical trials, provided moderate-quality evidence that short-term intake of flavanol-rich chocolate and cocoa products cause a small (2 $\mathrm{mmHg}$ ) blood pressure-lowering effect in healthy adults (Ried, Fakler, \& Stocks, 2017).

The anti-obesity potential of flavonols has been also explored. A meta-analysis based on 58 controlled clinical trials demonstrated that flavanols intake decreased body mass index and waist circumference (Akhlaghi, Ghobadi, Mohammad Hosseini, Gholami, \& Mohammadian, 2018). Finally, a systematic review based on 13 clinical trials concluded that "cocoa flavonols intake may improve vascular function, reduce exercise-induced oxidative stress, and alter fat and carbohydrate utilization during exercise, but without affecting exercise performance" (Decroix, Soares, Meeusen, Heyman, \& Tonoli, 2018).

\subsection{4 | Anthocyanins}

Anthocyanins (named from the Greek anthos, flower and kyáneos, blue), are shown in Figure 5. They are water-soluble flavonoids

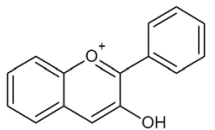

FIGURE 5 The structure backbone of anthocyanins<smiles>O=c1cc(-c2ccc(O)cc2)oc2cc(O)cc(O)c12</smiles>

(a) apigenin<smiles>O=c1cc(-c2ccc(O)c(O)c2)oc2cc(O)cc(O)c12</smiles>

(b) luteolin
FIGURE 6 The chemical structures of (a) apigenin and (b) luteolin

responsible for the color of fruits and flowers, which varies from red-orange to blue-violet. The basic structural unit of anthocyanins is the flavylium ion (2-phenylchromenylium; Pascual-Theresa \& Sanchez-Ballesta, 2008; Pervaiz et al., 2017). Most of the anthocyanins occur as acylated by organic acids (p-coumaric, sinapic, caffeic, ferulic, or sinapic acids) via ester bonds (Zhao et al., 2017). The common anthocyanins are cyanidin, delphinidin, malvidin, and peonidin. Black currants, red raspberry, elderberries, chokeberries, or strawberry, plums, pomegranates, blood orange, beans, cabbage, and red onions, are examples of anthocyanins sources (Albuquerque, Silva, Oliveira, \& Costa, 2018; Weber \& Larsen, 2017).

Anthocyanin clinical research has explored their possible relevance in cardiovascular diseases and complications, cognitive outcomes, and cancer. Promising, although not compelling clinical data, based on systematic review and meta-analysis, seem to suggest that anthocyanin supplementation may positively affect cholesterol and lipoprotein metabolism in patients with dyslipidaemia (Liu, Sun, Lu, \& Bo, 2016; Wallace, Slavin, \& Frankenfeld, 2016). Inhibition of lipid and glucose absorption from the gut, increase of cholesterol fecal excretion, and inhibition of cholesterol synthesis are the potential mechanisms involved. Also, a systematic review and meta-analysis of a prospective cohort studies has recently shown an inverse correlation between dietary intake of anthocyanins and risk of type-2 diabetes mellitus (Guo, Yang, Tan, Jiang, \& Li, 2016). The antioxidant and anti-inflammatory effects of anthocyanins are believed to be relevant for retarding the progression of type-2 diabetes (Liobikas, Skemiene, Trumbeckaite, \& Borutaite, 2016; Smeriglio, Barreca, Bellocco, \& Trombetta, 2016). More recently, a meta-analysis suggested a correlation between intake of dietary anthocyanins and reduced risk cardiovascular disease mortality (Kimble, Keane, Lodge, \& Howatson, 2018).

Robust preclinical evidence supports a beneficial role for anthocyanins in cognitive functions (Spencer, 2010). A recent systematic review, which included acute trials $(n=4)$ and longer term $(n=3)$ interventions that assessed multiple cognitive outcomes in 
subjects with cognitive impairment found improvements in six of seven studies retrieved after anthocyanin-rich food consumption. Improvements of the cognitive outcomes included verbal learning and memory after anthocyanin-rich food consumption (Kent, Charlton, Netzel, \& Fanning, 2017).

Finally, although anthocyanins experimentally inhibit cell growth, induce cell cycle arrest, stimulate apoptosis (or autophagy), and exerts anti-invasion and anti-metastatic actions, there are conflicting clinical results concerning the possible intake of anthocyanins and cancer prevention in humans (B. W. Lin et al., 2017).

\subsection{5 | Flavones}

The basic chemical structure of flavones consists of two benzene rings linked through a heterocyclic pyrone ring and the main flavones found in foods, luteolin, and apigenin (Figure 6). They are mainly present in their glycoside forms. Recently, Hostetler, Ralston, and Schwartz (2017) summarized, on the basis of existing studies, the concentration of flavones in teas and dry herbs, in juices and wines, in fruits, vegetables, olive oil, and honey. As instance, for wheat grain apigenin-cglycosides, a value of 2.1-mg/100-g dry weight has been observed (Wijaya \& Mares, 2012) and for black olives values of 6.5 and in the range 3.2-17.5-mg/100-g fresh weight for apigenin and luteolin, respectively (Bhagwat et al., 2014; Owen et al., 2003).

Examples of food sources are acerola, aprocot, cashew, bean, cabbage, cardon, dandelion, apple, artichoke, mango, papaya, and onion (Bataglion et al., 2015; Colla et al., 2013; Hussain et al., 2013; Siriamornpun \& Kaewseejan, 2017). There is evidence that dietary flavones intake may help reduce weight gain over time in population (Adriouch et al., 2018). Furthermore, a systematic review of epidemiological studies retrieved a cohort study in which a significant reduction between ovarian cancer incidence and kaempferol and luteolin intake was observed (Mohammadi, Dehghani, Larijani, \& Azadbakht, 2016).

Health-promoting and therapeutic beneficial effects, that is, on diabetes, amnesia, Alzheimer's disease, depression, insomnia, and cancer related to apigenin have been recently reported with reference to in vivo research, chemistry, and nutraceutical features (Salehi, Venditti, et al., 2019).

\subsection{6 | Isoflavones}

Isoflavones, shown in Figure 7, are biologically active compounds with estrogenic properties and often referred as phytoestrogen (Anandhi Senthilkumar, Fata, \& Kennelly, 2018; Xiao et al., 2018; Zaheer \& Humayoun Akhtar, 2017). The main representative components are genistein, daidzein, biochanin $A$, and glycitein.

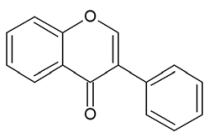

FIGURE 7 The structure backbone of isoflavones subclass
Isoflavones are found almost exclusively in the leguminous family of plants. Other sources are reported in apple, apricot, blackcurrant, cherry, cabbage, sweet potato, plum, date, onion, wheat, and melon pinapple (Abrankó, Nagy, Szilvássy, Stefanovits-Bányai, \& Hegedus, 2015; Bustamante-Rangel, Delgado-Zamarreño, Pérez-Martín, Rodríguez-Gonzalo, \& Domínguez-Álvarez, 2018; Konar, Poyrazoglu, Demir, \& Artik, 2012; Kuhnle et al., 2009). Isoflavone-containing preparations are promoted for alleviating menopausal symptoms. Accordingly, a systematic reviews and meta-analysis of the clinical data have been recently published on the potential beneficial effects of phytoestrogens on menopause and cancer prevention (Andrew \& Izzo, 2017). A systematic review and meta-analysis of clinical trials recently observed that specific phytoestrogen supplementation is associated with modest reductions of some menopausal symptoms such as hot flashes and vaginal dryness (Franco et al., 2016). There is also some evidence that phytoestrogens intake might exert cancer chemopreventive effects. A systematic review of observational data concluded that, despite some shortcomings, soy consumption consistent with a traditional Japanese diet, could reduce the risk of breast cancer incidence and recurrence (Fritz et al., 2013). A similar protective trend has been observed for prostate cancer risk reduction, although a firm conclusion cannot be drawn, given the size (number of patients) and duration of the individual trials (van Die, Bone, Williams, \& Pirotta, 2014).

In summary, the available evidences suggest that phytoestrogens may have a beneficial effect-although modest-on menopausal symptoms. Nonetheless, there is preliminary evidence that phytoestrogen intake could reduce the incidence of prostate and breast cancer.

\section{3 | Xanthones, stilbens, lignans, and tannins}

Xanthones, stilbenes, lignans, and tannins belong to non-flavonoids phenolic compounds (Durazzo, Lucarini, et al., 2018; González-Laredo, Rocha-Guzmán, Gallegos-Infante, Moreno-Jiménez, \& Gómez, 2018; Gutiérrez-Grijalva, Ambriz-Pére, Leyva-López, Castillo-López, \& Heredia, 2016; Kabera et al., 2014). They are compounds with at least two aromatic rings in the structure, whereas only tannins have more aromatic rings.

Xanthones, whose chemical structure is shown in Figure 8, are very stable molecules; they comprise a family of O-heterocycle symmetrical compounds with a dibenzo- $\gamma$-pyrone scaffold and are known as xanthone, xanthene-9-one, or dibenzo- $\gamma$-pyrone (Negi, Bisht, Singh, Rawat, \& Joshi, 2013). They have recently received more attention from food (Li, Thomas, \& Johnson, 2013) and pharmaceutical industries, involved in drug development because of their chemical structure, which allows them to interact with different drug targets (Gutierrez-Orozco \& Failla, 2013).

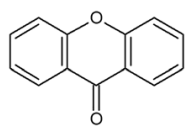

FIGURE 8 The structure backbone of xanthones subclass 
The principal natural sources of xanthones are the mangosteen fruit (Garcinia mangostana L.) and the mango fruit (Mangifera indica L.) (Gutierrez-Orozco \& Failla, 2013).

Their distinctive tricyclic aromatic ring exhibits a wide range of physiological properties and a protective potential as anticancer, antibacterial, anti-inflammatory, and antidiabetic (Li et al., 2013; Miura et al., 2001; Wezeman, Brase, \& Masters, 2015; Yasunaka et al., 2005).

The basic chemical structure of stilbenes (González-Laredo et al., 2018) consists into two benzene rings linked by a double bond, the $\mathrm{E}$ isomer being the most common configuration.

Stilbenes are reported to be present in grapes, almond, bean, blueberries, bilberries, peanuts, grapevine, cranberries, mulberries, plum, and wine (Arraki et al., 2017; Błaszczyk, Sady, \& Sielicka, 2019; Chang, Alasalvar, Bolling, \& Shahidi, 2017; Hassan, Saleh, \& AbdElgawad, 2018; Shrikanta, Kumar, \& Govindaswamy, 2015). The recent review of El Khawand, Courtois, Valls, Richard, and Krisa (2018) remarked how stilbenes present a high diversity in their phenolic structures (various chemical substituents and polymerization), which is a determining factor for their absorption and metabolism rates (El Khawand et al., 2018). The review of Reinisalo, Kårlund, Koskela, Kaarniranta, and Karjalainen (2015) summarized studies on the molecular mechanisms involved in the stilbene-mediated protection against oxidative stress in age-related diseases; the Nrf2/ARE pathway and CAMP second messenger system together are the key regulators of cellular antioxidant defence. Stilbenes can activate nuclear localization of Nrf2 and activation of Nrf2 target genes associated with antioxidant defence and autophagy (Reinisalo et al., 2015).

Stilbenes intake has been associated to a reduced all-cause mortality (Tresserra-Rimbau et al., 2014a) as well as to a reduced the risk of hypertension onset (Miranda, Steluti, Fisberg, \& Marchioni, 2016), diabetes (Tresserra-Rimbau et al., 2016), and obesity (Grosso et al., 2017; Grosso et al., 2018). The most known and studied among stilbenes is resveratrol, shown in Figure 9 (Annunziata, Tenore, \& Novellino, 2018; Koushki, Amiri-Dashatan, Ahmadi, Abbaszadeh, \& RezaeiTavirani, 2018; Ramírez-Garza et al., 2018; Tabeshpour, Mehri, Shaebani Behbahani, \& Hosseinzadeh, 2018). Although resveratrol exerts cardioprotective effects, a recent meta-analysis of available RCTs does not suggest any benefit of its supplementation on cardiovascular risk factors (Sahebkar et al., 2015). However, a further meta-analysis of 36 RCTs demonstrated that resveratrol intake significantly reduced weight, body mass index, WC, and fat mass and significantly increased lean mass (Tabrizi et al., 2018).

Lignans are diphenolic compounds derived from the combination of two phenylpropanoid C6-C3 units at the $\beta$ and $\beta^{\prime}$ carbon atoms and can be linked to additional ether, lactone, or carbon bonds; they have a 1,4-diarylbutan like chemical structure (Lewis \& Davin, 1999)

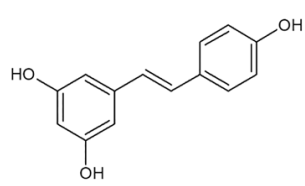

FIGURE 9 The chemical structure of resveratrol and are derived from the shikimic acid biosynthetic pathway (Imai, Nomura, \& Fukushima, 2006). Lignans are vascular plant secondary metabolites, with widespread occurrence in the plant kingdom and to which are attributed a wide range of physiological properties, positively influencing human health (Durazzo, 2018a). As reported by Durazzo, Lucarini, et al. (2018), in a review on the occurrence of lignans in food groups, which also summarizes the main national databases of lignans, the main sources of dietary lignans are oilseeds (i.e., flax, soy, rapeseed, and sesame), whole-grain cereals (i.e., wheat, oats, rye, and barley), legumes, various vegetables, and fruit (particularly berries), as well as beverages, such as coffee, tea, and wine, and, recently, lignans are also reported in dairy products, meat, and fish. The main dietary lignans are secoisolariciresinol, matairesinol, lariciresinol, pinoresinol, medioresinol, and syringaresinol (shown in Figure 10).

The intake of lignans has been mostly related to their possible cancer chemopreventive actions (due to their phytoestrogen properties) and in the prevention of cardiovascular diseases (Anandhi Senthilkumar et al., 2018; Xiao et al., 2018).

A meta-analysis, which included 21 studies (11 prospective cohort studies and 10 case-control studies), found that high lignan exposure may be associated with a reduced breast cancer risk in postmenopausal women (Buck, Zaineddin, Vrieling, Linseisen, \& Chang-Claude, 2010). However, a further and more recent meta-analysis of 143 of prospective supports the need for a more conservative evaluation of the clinical aspects (Grosso et al., 2017).

A study aiming at examining total and individual lignan intakes in 2,599 postmenopausal women found that total and individual lignan intake (i.e., matairesinol, pinoresinol, and secoisolariciresinol) were not associated with the prevalence of cardiovascular diseases and its risk factors, whereas the intake of lariciresinol was linked to a reduced hypercholesterolemia (Witkowska et al., 2018).

Also, a meta-analysis assessed the association between dietary flavonoid and lignan intake with all-cause and cardiovascular disease mortality in prospective cohort studies. As a result, only limited evidence for lignans intake and all-cause mortality was evidenced (Grosso et al., 2017).

Tannins are classified into two major groups: hydrolyzable and non-hydrolyzable tannins, also called condensed tannins or proanthocyanidins (Durazzo, 2018b; Kabera et al., 2014; Smeriglio, Barreca, Bellocco, \& Trombetta, 2017). Proanthocyanidins, namely, condensed tannins, are oligomers and polymers consisting from two to more than 200 monomers of flavan-3-ol units (M. H. Chen, Mcclung, \& Bergman, 2016; Serrano, Puupponen-Pimiä, Dauer, Aura, \& Saura-Calixto, 2009). Hydrolyzable tannins are further categorized into gallotannins and ellagitannins (Arapitsas, 2012; Jakobek, 2015). As instance, numerous studies are present on biological and biomedical functions of penta-O-galloyl-D-glucose and its derivatives (Cao et al., 2014; Zhang, Li, Kim, Hagerman, \& Lü, 2009). Another study of Ma et al. (2015) showed how the hydrolyzable gallotannin, pentaO-galloyl- $\beta$-D-glucopyranoside, inhibits the formation of advanced glycation endproducts by protecting the protein structure.

Tannins can also be divided, according to their constitutive monomers and chemical structures, into four groups: proanthocyanidins, 
<smiles>COc1cc(CC(CO)C(CO)Cc2ccc(O)c(OC)c2)ccc1O</smiles>

(a) secoisolariciresinol<smiles>COc1cc(CC2COC(c3ccc(O)c(OC)c3)C2CO)ccc1O</smiles>

(c) lariciresinol<smiles>COc1cc(CC2COC(=O)C2Cc2ccc(O)c(OC)c2)ccc1O</smiles>

(b) matairesinol<smiles>COc1cc(C2OCC3C(c4ccc(O)c(OC)c4)OCC23)ccc1O</smiles>

(d) pinoresinol<smiles>COc1cc(C2OCC3C(c4cc(OC)c(O)c(OC)c4)OCC23)cc(C2OCC3C(c4cc(OC)c(O)c(OC)c4)OCC23)c1</smiles>

(e) medioresinol

(f) syringaresinol
FIGURE 10 The chemical structures of main dietary lignans, (a) secoisolariciresinol, (b) matairesinol, (c) lariciresinol, (d) pinoresinol, (e) medioresinol, (f) syringaresinol hydrolyzable tannins, phlorotannins, and complex tannins (Serrano et al., 2009). Phlorotannins are oligomers, or polymers of phloroglucinol (1,3,5-trihydroxybenzene), that are produced by brown algae (Phaeophycea; Corona et al., 2016; Leyton et al., 2016). They consist in subgroups: fuhalos and phlorethols (ether linkage), fucols (phenyl linkage), fucophlorethols (ether and phenyl linkage), eckols, and carmalols (dibenzodioxin linkage; Corona et al., 2016).

Complex tannins present a complex structural of different groups as examples gallotannin or ellagitannin units linked to catechin or epicatechin (Serrano et al., 2009).

Tannins are reported to be constituent of legumes such as beans (Boudjou, Oomah, Zaidi, \& Hosseinian, 2013; Campos-Vega et al., 2009; Chen et al., 2018), fruits, particularly berries (Fischer, Jaksch, Carle, \& Kammerer, 2013; Hellström \& Mattila, 2008; Kalili, Vestner Stander, \& de Villiers, 2013), and nuts (Bittner, Rzeppa, \& Humpf, 2013).

Dietary supplements containing proanthocyanidins include cranberry juice (Vaccinium macrocarpon), a top-selling herbal supplement used for the prevention of urinary tract infections, pine bark (Pinus pinaster, subsp. atlantica) extracts, marketed for preventing/treating a wide range of chronic conditions without compelling evidence of efficacy (Andrew \& Izzo, 2017), and grape (Vitis vinifera) seeds, which, based on a meta-analysis of nine small randomized clinical trials ( $n=390$ patients in total), appeared to lower heart rate and systolic blood pressure (Feringa, Laskey, Dickson, \& Coleman, 2011).

An Italian case-control study, including a total of 1,294 case studies, showed that proanthocyanidin consumption was inversely associated to prostate cancer risk (Praud et al., 2018). Also, in a population of 948 women aged over 75 years, proanthocyanidin intake was associated with better renal function and reduced renal associated events (Ivey et al., 2013).

\section{3 | POLYPHENOL INTAKE AND HUMAN HEALTH}

\section{1 | Cardiovascular diseases}

Cardiovascular diseases, including coronary artery diseases, stroke, heart failure, and hypertension, are the first cause of death in Western countries. A large number of naturally occurring compounds and foods are promoted for the prevention of such diseases (Allawadhi, Khurana, Sayed, Kumari, \& Godugu, 2018; Tapsell, Neale, \& Probst, 2019). 
Accordingly, a number of observational and intervention studies has explored the possible association between the intake of polyphenolrich foods (e.g., beverages such as cocoa, fruit and vegetables, tea, extra virgin/virgin olive oil, and wine) and cardiovascular diseases.

In a 7,447 participants, parallel group, randomized, multicenter, controlled 5-year feeding trial, Tresserra-Rimbau et al. (2014a) showed a $37 \%$ relative reduction in all-cause mortality comparing the highest with the lowest quintiles of total polyphenol intake (Tresserra-Rimbau et al., 2014a; Tresserra-Rimbau et al., 2014b). Among the polyphenol subclasses, stilbenes and lignans were significantly associated with reduced all-cause mortality (Tresserra-Rimbau et al., 2014a). Similarly, a population-bases cohort-study, which included 807 men and women aged 65 years and older, from the Italian Chianti region of Tuscany (Italy), suggested that an high dietary intake of polyphenols in the diet may be associated with longevity (Tresserra-Rimbau et al., 2013).

An observational study assessing the association between intakes of total polyphenol and polyphenol subgroups and the risk of major cardiovascular events (myocardial infarction, stroke, or death from cardiovascular causes) revealed a $46 \%$ reduction of cardiovascular diseases risk comparing the population with the highest intake of polyphenols versus the population with the lowest intake. The polyphenols with the strongest inverse associations were flavanols, lignans, and hydroxybenzoic acids (Tresserra-Rimbau et al., 2014b).

\section{2 | Inflammatory cardiovascular risk}

Medina-Remón et al. (2017) found that an increase in polyphenol intake, measured as urinary total polyphenol excretion, was associated to decreased inflammatory biomarkers (i.e., vascular cell adhesion molecule, intercellular adhesion molecule, interleukin, tumor necrosis factor alpha, and monocyte chemotactic protein). Furthermore, high polyphenol intake reduced cardiovascular risk factors, with a positive effect on blood pressure and lipid profile (Medina-Remón et al., 2017).

In summary, clinical evidence suggests that polyphenols intake may reduce the risk of cardiovascular diseases. Although it is not completely clear how polyphenols exerts their protective effects, it is believed that modulation of nitric oxide production and induction of antioxidant defences may play an important role (Costa et al., 2017).

\section{3 | Hypertension}

High blood pressure is the major risk factor for cardiovascular diseases. Consumption of polyphenol-rich food has been associated with an improvement in endothelial function via the NO-cGMP pathway and ACE inhibition (Hügel, Jackson, May, Zhang, \& Xue, 2016).

A cross-sectional study of 589 elderly at high cardiovascular risk revealed an inverse association between urinary total polyphenol excretion and the prevalence of hypertension. Specifically, participants in the highest quartile of urinary total polyphenol excretion had a reduced prevalence of hypertension compared with those in the lowest quartile (Medina-Remon et al., 2011). An analysis of individual subclasses of polyphenols revealed an inverse association between the highest tertile of tyrosols, alkylphenols, lignans, and stilbene and hypertension in a general Brasilian population (Miranda et al., 2016). A meta-analysis specifically focused on grape polyphenols showed, on the basis of ten retrieved studies, that daily grape polyphenol consumption reduced systolic blood pressure by $1.48 \mathrm{mmHg}$ when compared with control participants. Diastolic blood pressure was unmodified (Li, Zhao, Tian, Chen, \& Cui, 2015).

There is also clinical evidence that gender may influence the beneficial properties of polyphenols (Bacchetti, Turco, Urbano, Morresi, \& Ferretti, 2018). Grosso et al. (2018) found that subjects with the highest quartile of total polyphenol consumption have a $31 \%$ decreased risk of hypertension compared with the lowest intake in women, but this has not been onbserved in men. Associations were found also with hydroxycynnamic acids and flavanols intake (Grosso et al., 2018).

Finally, a randomized study in which subjects were randomized to receive either a low-polyphenol diet for 8 weeks or to consume a high-polyphenol diet (based on the intake of fruits, vegetables, berries, and dark chocolate) showed that increasing the dietary polyphenol intake caused a significant improvement in microvascular function in hypertensive participants (Noad et al., 2016).

\section{4 | Diabetes}

There is evidence that high intake of polyphenols may reduce the risk of diabetes. Tresserra-Rimbau et al. (2016) prospectively examined the associations between the intake of polyphenols on the risk of incident diabetes in an observational cohort analysis including 18,900 nondiabetic elderly at high risk of cardiovascular disease. It was observed a $28 \%$ reduction in new-onset diabetes in the highest compared with the lowest tertile of total polyphenol intake. Among polyphenol subclasses, stilbenes and flavanones intake was associated with a reduced risk (Tresserra-Rimbau et al., 2016).

Recently, a meta-analysis of 18 prospective epidemiologic studies, which investigated the association between polyphenols (51 different compounds in total) and type 2 diabetes, revealed inverse associations for intakes of different subclasses and individual polyphenols, including flavonoids, flavonols, flavan-3-ols, catechins, anthocyanidins, isoflavones, daidzein, genistein, and stilbenes (Rienks et al., 2018).

\section{5 | MetS and obesity}

MetS is a clustering of metabolic abnormalities that may include hypertension, central obesity, insulin resistance, hypertension, and dyslipidemia. It is strongly associated with an increased risk for developing cardiovascular diseases and type-2 diabetes. Management of MetS includes lifestyle modifications, pharmacotherapy, and a nutraceutical approach (Finicelli et al., 2019; Rochlani, Pothineni, Kovelamudi, \& Mehta, 2017; Santini et al., 2017; Santini \& Novellino, 2017b).

Evidence regarding the effectiveness of polyphenols in preventing or delaying the physiopathological components accountable for MetS onset has been provided (Amiot et al., 2016; Finicelli et al., 2019). In an 
observational Iranian study, higher intake of flavonoids-but not total polyphenol intake and other subclasses of polyphenol-was inversely associated with risk of developing MetS and hypertriglyceridemia (Sohrab et al., 2018). Furthermore, a cohort study cross-sectional population-based survey including 8,821 adults in Eastern Europe found that dietary polyphenols intake was inversely associated with MetS and its effects such as waist circumference, blood pressure, high lipoprotein cholesterol, and triglycerides in women. It was found also to be associated with fasting plasma glucose in both genders (Grosso et al., 2018). Among polyphenol subclasses, phenolic acids have been associated with blood pressure and triglycerides, whereas phenolic acids and stilbenes with MetS. Flavonoids have been related with fasting plasma glucose and lignans and stilbenes with waist circumference. Hydroxycinnamic acids, flavanols, and dihydrochalcones had the most prominent effect (Grosso et al., 2018).

Adriouch et al. (2018) provided evidence that dietary polyphenol consumption might have favorable effect on weight gain in the general population over a 6-year period of time (Adriouch et al., 2018). Waist circumference and body mass index were differently affected by the diverse polyphenol subclasses. Specifically, flavanones, flavones and lignans intake resulted in less notable increase in body mass index; flavanones, flavones, hydroxycinnamic acids, and lignans intake was associated to a less notable increase in waist circumference (Adriouch et al., 2018). A cross-sectional study was performed with 573 participants at high cardiovascular risk; after 5-year follow-up, significant inverse correlation between total urinary polyphenol excretion and body weight, body mass index, waist circumference, and waist-to-height ratio was observed (Guo et al., 2017)

Finally, a systematic review of 19 randomized controlled trials concluded that further research is required before suggesting a role of polyphenol intake in reducing weight in overweight and obese individuals. Only nine out of 19 trials studies showed a significant decrease in weight (Farhat et al., 2017). Further larger trials with a duration of 12 months or more are needed to elucidate the effect of polyphenols on body weight status.

\section{6 | Cancer}

Most naturally occurring ingredients with consistently reported anticancer efficacy contains high levels of polyphenols (Oyenihi \& Smith, 2019; Tariq et al., 2017). Polyphenols have demonstrated chemopreventive efficacy against experimental tumors, via antiinitiating, anti-promoting, anti-progression, and anti-angiogenesis actions, as well as by modulating the immune system (Asadi-Samani, Bagheri, Rafieian-Kopaei, \& Shirzad, 2017; Erices, Torres, Niechi, Bernales, \& Quezada, 2018; Mileo \& Miccadei, 2016; Rengasamy et al., 2019; Salehi et al., 2018; Xing, Zhang, Qi, Tsao, \& Mine, 2019).

Also, polyphenol anticancer actions involve redox changes, modulation of enzymes, and signaling kinases resulting to effects on multiple genes and cell signaling pathways (Maru, Hudlikar, Kumar, Gandhi, \& Mahimkar, 2016; Mileo \& Miccadei, 2016). Despite encouraging experimental data, clinical results have not provided univocal results and should be also mentioned that some polyphenols, such as genistein and daidzein, might adversely affect hormone-related cancer (Zhou et al., 2016)

The dietary assessment and the role in the prevention of cancer by polyphenols have been systematically reviewed (Grosso, Godos, et al. 2017) in an analysis including 143 clinical studies. Meta-analyses of prospective studies showed that isoflavones intake was significantly associated with decreased risk of lung and gastric cancer and, to a lesser extent, to breast and colorectal cancers (Grosso, Godos, et al., 2017). Meta-analyses of case-control studies showed that flavonoids intake was associated with a decreased risk of gastrointestinal, breast, and lung cancer. However, despite a large number of epidemiological studies have investigated the relation between dietary polyphenols and cancer, the evidence is not fully consistent, and further larger studies are needed.

Similar conclusions were given by Rothwell, Knaze, and ZamoraRos (2017), who have recently summarized the epidemiological evidence for associations between cancer risk and polyphenol intake (Rothwell et al., 2017). Epidemiological studies have found that the intake of flavonoids, the most studied subgroup of polyphenols with regard to cancer risk, have been rarely associated with a reduction in cancer risk itself. There is some evidence that isoflavones, whose main dietary sources are soy foods, might possibly reduce the risk of some type of cancer (i.e., colorectal, breast, and prostate cancers), particularly in Asian countries (Rothwell et al., 2017).

\section{4 | PHENOLIC COMPOUNDS AND DATABASES}

The need for categorization of polyphenols and for the implementation of specific and dedicated databases emerged, based on both analytical data and collected data taken from literature throughout a harmonized and standardized approach for the evaluation of an adequate dietary intake (Durazzo et al., 2018; Durazzo, Lucarini, et al., 2018).

Nowadays, the main core public databases, gathering extensive data on the polyphenol content of foods and beverages are (a) the United States Department of Agriculture (USDA) databases (USDA website https://www.usda.gov/); (b) the Phenol-Explorer (PhenolExplore website http://phenol-explorer.eu/; Neveu et al., 2010); (c) the eBASIS-Bioactive Substances in Food Information Systems (eBASIS website http://www.eurofir.org/our-tools/ebasis/; Kiely et al., 2010; Plumb et al., 2017).

Phenol-Explorer was the first comprehensive web-based openacces database on polyphenol content in foods, including data on pharmacokinetic and metabolites, the effect of food processing and cooking throughout several updates (Rothwell et al., 2012; Rothwell et al., 2013) and including lignans data in the current version 3.6; data were collected from peer-reviewed scientific publications and evaluated before they were aggregated to produce final representative mean content values. 


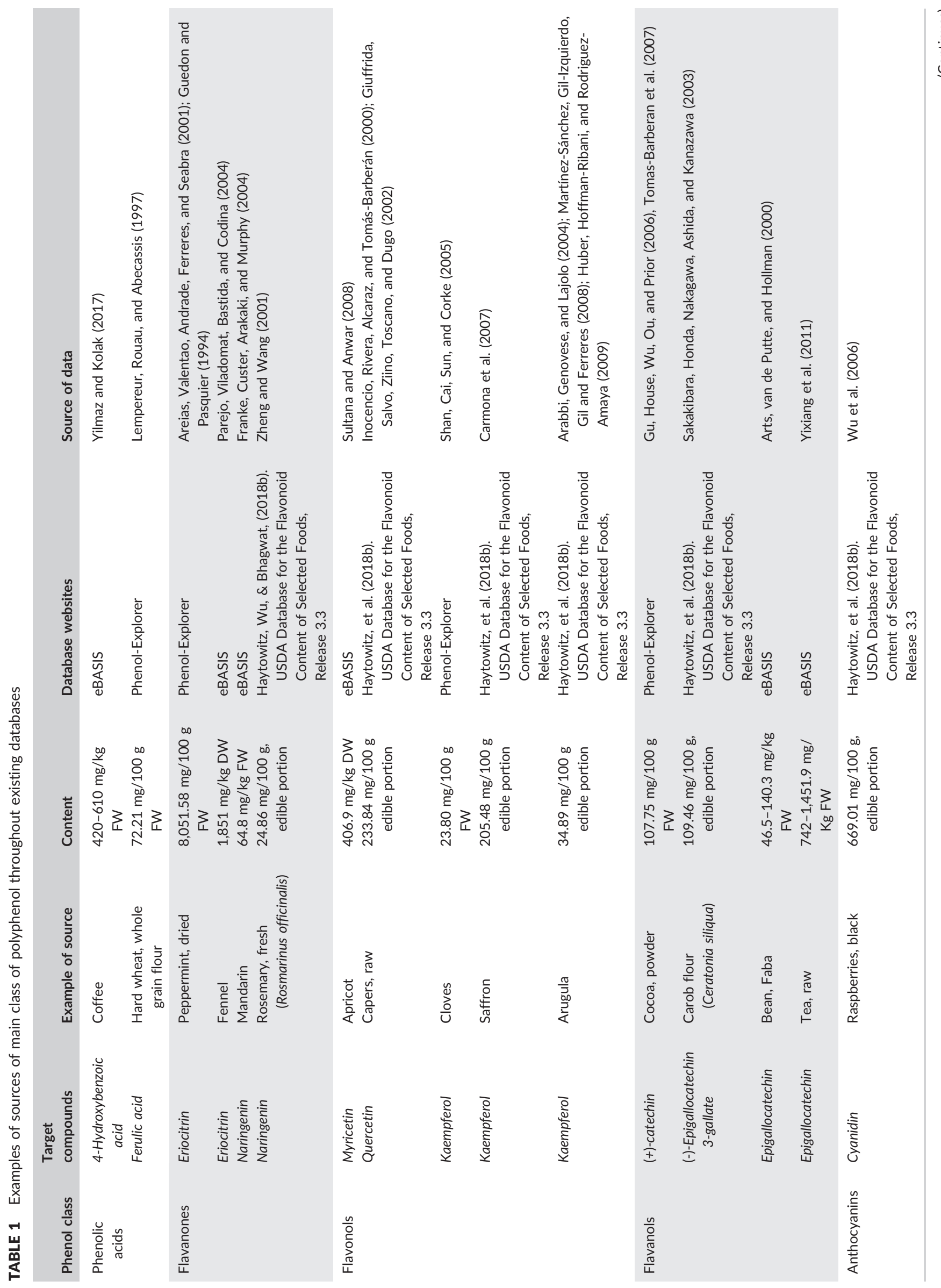



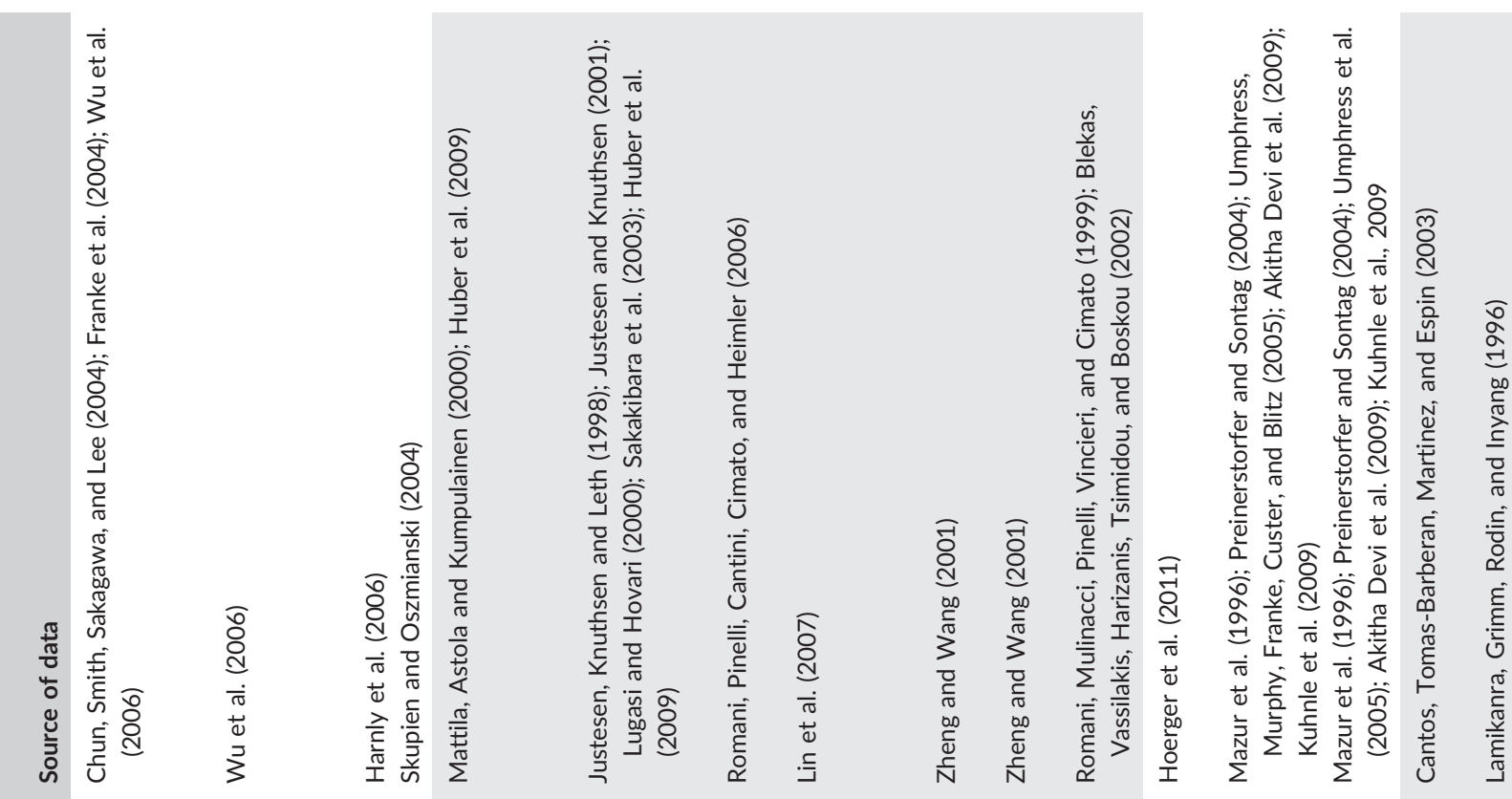

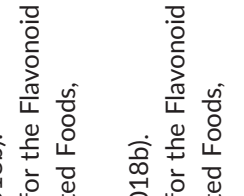

\%

흥

$\frac{7}{\frac{0}{0}}$

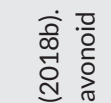

$\begin{array}{llll} & \\ 0 & & \\ 0\end{array}$

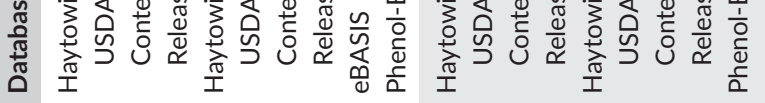

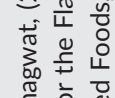

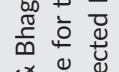

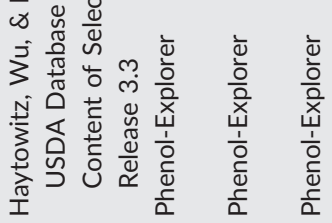

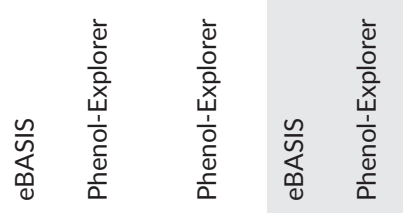

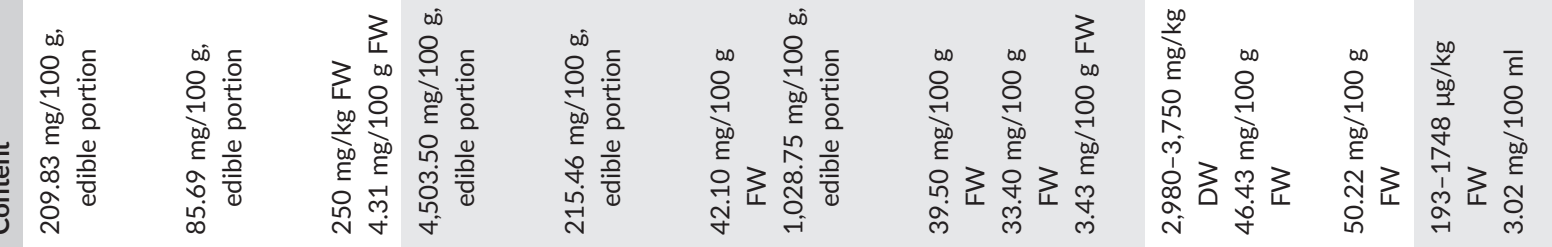

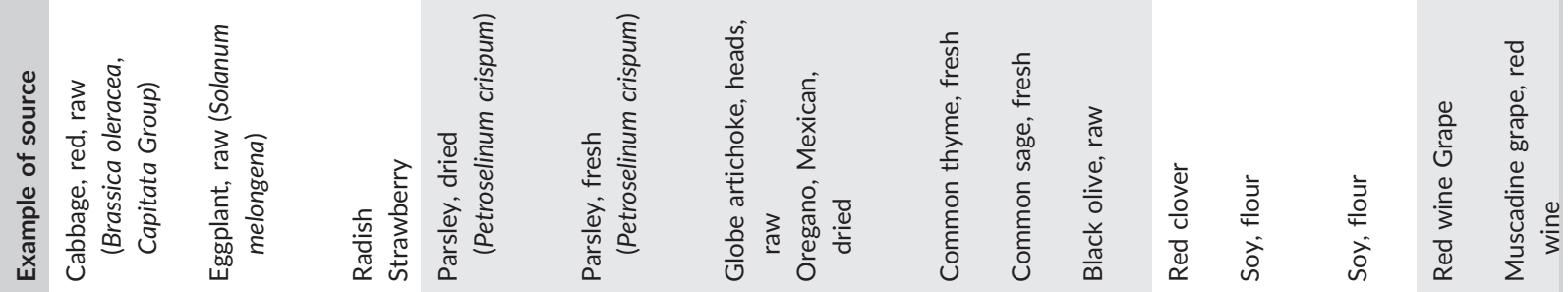

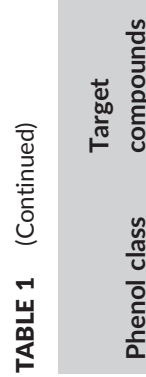

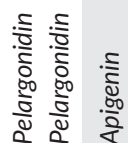

$\frac{.5}{\frac{.0}{2}}$

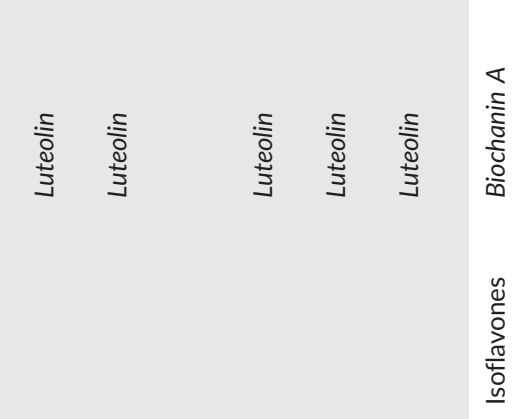

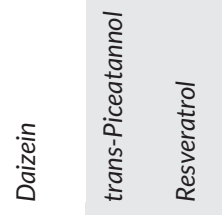<smiles>[CH][CH]</smiles> 


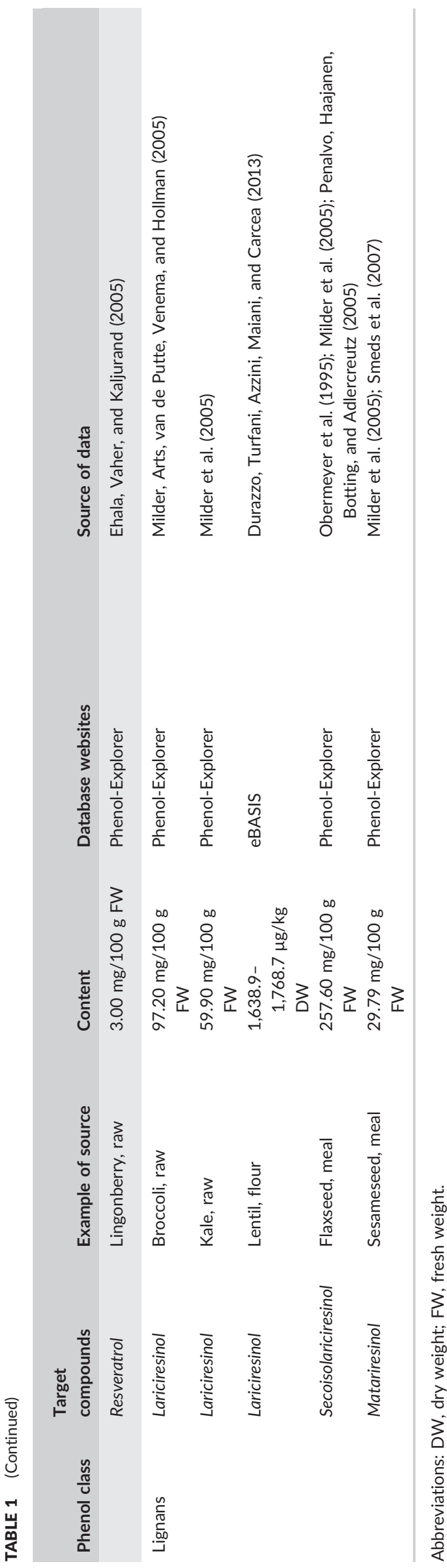

The USDA database, based on a compilation of data from literature, was developed in 2004 and expanded in recent years with inclusion of flavonoids, proanthocyanidins, and isoflavones (Bhagwat et al., 2014; Haytowitz, Wu, \& Bhagwat, 2018a, b).

eBASIS should be defined as the first European Union (EU) harmonized food composition database: contains composition data and biological effects of over 300 major European plant foods of 24 compound classes, such as glucosinolates, phytosterols, polyphenols, isoflavones, glycoalkaloids, and xanthine alkaloids in 15 EU languages (Plumb et al., 2017). It is based on the compilation of expert, who critically evaluated data extracted from peer-reviewed literature as raw data. Currently, data points inserted in eBASIS for phenolic compounds were 639 for simple phenols, 3,616 for flavanols, 1,039 for flavones, 1,733 for flavanones, 3,669 for flavonols, 4,541 for anthocyanins, 6,543 for isoflavones, 2,695 for lignans, 405 for stilbenes, and 533 for proanthocyanidins (eBASIS website http://www. eurofir.org/our-tools/ebasis/; Plumb et al., 2017). Table 1 reports examples of the sources of the main class of polyphenol as reported throughout exisiting databases.

Indeed, related to the role of biologically active compounds in humans, it is worth mentioning the Human Metabolome Database or HMDB 4.0 (HMDB website http://www.hmdb.ca/), a web metabolomic database on human metabolites (Wishart et al., 2018), and PhytoHub (Phytohub website http://phytohub.eu/), a freely electronic database on phytochemicals commonly ingested in diets, and their metabolites (Bento da Silva et al., 2016).

\section{5 | CONCLUSION}

This updated picture reports key concepts in polyphenol research and highlights new frontiers of polyphenols in nutrition and health. In summary, clinical evidence suggests that polyphenols intake could possibly reduce the risk of cardiovascular diseases. Concerning the association between polyphenols and type 2 diabetes, it is worth mentioning a recent meta-analysis of 18 prospective epidemiologic studies, which revealed inverse associations for intakes of different subclasses and individual polyphenols (Rienks et al., 2018). Further research is required before suggesting a role of polyphenol intake in reducing weight in overweight and obese individuals. Regarding the relation between dietary polyphenols and cancer, despite a large number of epidemiological studies, the evidence is not fully consistent, and further larger studies are needed.

The research end point on polyphenols should be addressed towards two main directions: (a) the identification of new structures of polyphenols throughout innovatitive advanced technologies; (b) the studies of bioactivities, starting from the evaluation of interactions between compounds by in vitro assays, throughout studies on cell lines and animal models, to bioavailability and intervention studies until epidemiological and clinical trials in humans. Both studies pathways are interconnected, and an integrated and multidisciplinary approach of research, in terms of health benefits, must be considered necessary to achieve the above mentioned end point. In this regard, the use of nanotechnologies for micro and nanodelivery polyphenol- 
target formulations represent a new frontier for better target tissues and organs and enhance the therapeutic efficacy of polyphenols.

Ultimately, considering the potential beneficial health effect of polyphenols, the exploitation of food waste and of different/unconventional matrixes as alternative sources in terms of polyphenols should be pursued.

\section{CONFLICT OF INTEREST}

The authors declare that they do not have any conflict of interest to disclose.

\section{ORCID}

Alessandra Durazzo (D) https://orcid.org/0000-0002-7747-9107

Massimo Lucarini (1) https://orcid.org/0000-0001-6178-9779

Eliana B. Souto (ID https://orcid.org/0000-0002-9737-6017

Carla Cicala (D) https://orcid.org/0000-0002-8977-8251

Elisabetta Caiazzo (1) https://orcid.org/0000-0002-5667-5176

Angelo A. Izzo (1) https://orcid.org/0000-0002-8557-2133

Ettore Novellino (D) https://orcid.org/0000-0002-2181-2142

Antonello Santini (i) http://orcid.org/0000-0001-5505-3327

\section{REFERENCES}

Abenavoli, L., Izzo, A. A., Milić, N., Cicala, C., Santini, A., \& Capasso, R. (2018). Milk thistle (Silybum marianum): A concise overview on its chemistry, pharmacological, and nutraceutical uses in liver diseases. Phytotherapy Research, 32(11), 2202-2213. https://doi.org/10.1002/ ptr.6171

Abraham, K., Wöhrlin, F., Lindtner, O., Heinemeyer, G., \& Lampen, A. (2010). Toxicology and risk assessment of coumarin: focus on human data. Molecular Nutrition and Food Research, 54(2), 228-239.

Abrankó, L., Nagy, A., Szilvássy, B., Stefanovits-Bányai, E., \& Hegedus, A. (2015). Genistein isoflavone glycoconjugates in sour cherry (Prunus cerasus L.) cultivars. Food Chemistry, 166, 215-222.

Adriouch, S., Kesse-Guyot, E., Feuillet, T., Touvier, M., Olié, V., Andreeva, V., ... Fezeu, L. K. (2018). Total and specific dietary polyphenol intakes and 6-year anthropometric changes in a middle-aged general population cohort. International Journal of Obesity (Lond), 42(3), 310-317.

Akhlaghi, M., Ghobadi, S., Mohammad Hosseini, M., Gholami, Z., \& Mohammadian, F. (2018). Flavanols are potential anti-obesity agents, a systematic review and meta-analysis of controlled clinical trials. Nutrition Metabolism Cardiovascular Disease, 28(7), 675-690.

Akitha Devi, M. K., Mahendranath, G., Sakthivelu, G., Giridhar, P., Rajasekaran, T., \& Ravishankar, G. A. (2009). Functional attributes of soybean seeds and products, with reference to isoflavone content and antioxidant activity. Food Chemistry, 114, 771-776.

Alam, M. A., Subhan, N., Hossain, H., Hossain, M., Reza, H. M., Rahman, M. M., \& Ullah, M. O. (2016). Hydroxycinnamic acid derivatives: A potential class of natural compounds for the management of lipid metabolism and obesity. Nutrition \& Metabolism (London), 13, 27. https://doi.org/ 10.1186/s12986-016-0080-3 eCollection 2016

Albuquerque, T. G., Silva, M. A., Oliveira, M. B. P. P., \& Costa, H. S. (2018) Chapter 34-Analysis, identification, and quantification of anthocyanins in fruit juices. In G. Rajauria, \& B. K. Tiwari (Eds.), Fruit juices extraction, composition, quality and analysis (pp. 693-737). Amsterdam, Holland: Academic Press, Elsevier.

Allawadhi, P., Khurana, A., Sayed, N., Kumari, P., \& Godugu, C. (2018). Isoproterenol-induced cardiac ischemia and fibrosis: Plant-based approaches for intervention. Phytotherapy Research, 32(10), 1908-1932.

Amarowicz, R., Carle, R., Dongowski, G., Durazzo, A., Galensa, R., Kammerer, D., ... Piskula, M. K. (2009). Influence of postharvest processing and storage on the content of phenolic acids and flavonoids in foods. Molecular Nutrition and Food Research, 53, S151-S183. ISSN: 1613-4125. https://doi.org/10.1002/mnfr.200700486

Amiot, M. J., Riva, C., \& Vinet, A. (2016). Effects of dietary polyphenols on metabolic syndrome features in humans: A systematic review. Obesity, 17, 573-586.

Anandhi Senthilkumar, H., Fata, J. E., \& Kennelly, E. J. (2018). Phytoestrogens: The current state of research emphasizing breast pathophysiology. Phytotherapy Research, 32(9), 1707-1719.

Andres, S., Pevny, S., Ziegenhagen, R., Bakhiya, N., Schäfer, B., HirschErnst, K. I., \& Lampen, A. (2018). Safety aspects of the use of quercetin as a dietary supplement. Molecular Nutrition and Food Research, 62(1). https://doi.org/10.1002/mnfr.201700447

Andrew, R., \& Izzo, A. A. (2017). Principles of pharmacological research of nutraceuticals. British Journal of Pharmacology, 174(11), 1177-1194.

Annunziata, G., Maisto, M., Schisano, C., Ciampaglia, R., Daliu, P., Narciso V., ... Novellino, E. (2018). Colon bioaccessibility and antioxidant activity of white, green and black tea polyphenols extract after in vitro simulated gastrointestinal digestion. Nutrients, 10(11). pii: E1711). https://doi.org/10.3390/nu10111711

Annunziata, G., Tenore, G. C., \& Novellino, E. (2018). Resveratrol-based nutraceuticals for the management of diabetes and obesity: Real therapeutic potential or a mere palliative? Archives of Diabetes \& Obesity, 1(2). https://doi.org/10.32474/ADO.2018.01.000109

Arabbi, P. R., Genovese, M. I., \& Lajolo, F. M. (2004). Flavonoids in vegetable foods commonly consumed in Brazil and estimated ingestion by the Brazilian population. Journal of Agricultural and Food Chemistry, 52(5), 1124-1131.

Arapitsas, P. (2012). Hydrolyzable tannin analysis in food. Food Chemistry, 135, 1708-1717.

Areias, F. M., Valentao, P., Andrade, P. B., Ferreres, F., \& Seabra, R. M. (2001). Phenolic fingerprint of peppermint leaves. Food Chemistry, 73, 307-311.

Arraki, K., Renouf, E., Waffo-Teguo, P., Mérillon, J. M., Tristan Richard, T., \& Decenditet, A. (2017). Identification and quantification of stilbenes in some Tunisian red wines using UPLC-MS and HPLC-DAD. OENO One, 51(3). https://doi.org/10.20870/oeno-one.2017.51.2.1673

Arts, I. C. W., van de Putte, B., \& Hollman, P. C. H. (2000). Catechin contents of foods commonly consumed in the Netherlands. Fruits, vegetables, staple foods and processed foods. Journal of Agricultural and Food Chemistry, 48, 1746-1751.

Asadi-Samani, M., Bagheri, N., Rafieian-Kopaei, M., \& Shirzad, H. (2017). Inhibition of Th1 and Th17 cells by medicinal plants and their derivatives: A systematic review. Phytotherapy Research, 31(8), 1128-1139. https://doi.org/10.1002/ptr.5837

Atkin, S. L., Katsiki, N., Derosa, G., Maffioli, P., \& Sahebkar, A. (2017). Curcuminoids lower plasma leptin concentrations: A meta-analysis. Phytotherapy Research, 31(12), 1836-1841.

Azzini, E., Maiani, G., Garaguso, I., Polito, A., Foddai, M. S., Venneria, E., ... Nobili, F. (2016). The potential health benefits of polyphenol rich extracts from Cichorium intybus L. studied on Caco-2 cells model. Oxidative Medic and Cellular Longevity, 3, 1-9. https://doi.org/10.1155/ 2016/1594616

Bacchetti, T., Turco, I., Urbano, A., Morresi, C., \& Ferretti, G. (2018). Relationship of fruit and vegetable intake to dietary antioxidant capacity 
and markers of oxidative stress: A sex-related study. Nutrition, 61, 164-172.

Bajkacz, S., \& Adamek, J. (2017). Development of a method based on natural deep eutectic solvents for extraction of flavonoids from food samples. Food Analytical Methods, 11, 1330-1344.

Barbosa, P. P. M., Ruviaro, A. R., \& Macedo, G. A. (2018). Comparison of different Brazilian citrus by-products as source of natural antioxidants. Food Science Biotechnology, 27(5), 1301-1309.

Barreca, D., Gattuso, G., Bellocco, E., Calderaro, A., Trombetta, D., Smeriglio, A., ... Nabavi, S. M. (2017). Flavanones: Citrus phytochemical with health-promoting properties. BioFactors, 43(4), 495-506. https:// doi.org/10.1002/biof.1363

Bataglion, G. A., da Silva, F. M. A., Eberlin, M. N., \& Koolen, H. H. F. (2015). Determination of the phenolic composition from Brazilian tropical fruits by UHPLC-MS/MS. Food Chemistry, 180, 280-287.

Belwal, T., Nabavi, S. F., Nabavi, S. M., \& Habtemariam, S. (2017). Dietary anthocyanins and insulin resistance: When food becomes a medicine. Nutrients, 9(10). pii: E1111

Bento da Silva, A., Giacomoni, F., Pavot, B., Fillâtre, Y., Rothwell, J.A., Sualdea, B.B., ... Manach, C. (13-15 September 2016). PhytoHub V1.4: A new release for the online database dedicated to food phytochemicals and their human metabolites. In Proceedings of the 1st International Conference on Food Bioactivities \& Health, Norwich, UK.

Bernatoniene, J., \& Kopustinskiene, D. M. (2018). The role of catechins in cellular responses to oxidative stress. Molecules, 23, 965. https://doi. org/10.3390/molecules23040965

Bhagwat, S., Haytowitz, D. B., \& Holden, J. M. (2014). USDA database for the flavonoid content of selected foods. Release3.1; U.S. Department of Agriculture, Agricultural Research Service, Nutrient Data Laboratory: Beltsville, MD, USA. Retrieved from https://data.nal.usda.gov/dataset/ usda-database-flavonoid-content-selected-foods-release-31-may2014_109 (accessed on 19 May 2019).

Białecka-Florjańczyk, E., Fabiszewska, A., \& Zieniuk, B. (2018). Phenolic acids derivatives-Biotechnological methods of synthesis and bioactivity. Current Pharmacology Biotechnology. https://doi.org/10.2174/ 1389201020666181217142051

Biesalski, H. K., Dragsted, L. O., Elmadfa, I., Grossklaus, R., Müller, M., Schrenk, D., ... Weber, P. (2009). Bioactive compounds: Definition and assessment of activity. Nutrition, 25, 1202-1205. https://doi.org/ 10.1016/j.nut.2009.04.023

Bittner, K., Rzeppa, S., \& Humpf, H. U. (2013). Distribution and quantification of flavan-3-ols and procyanidins with low degree of polymerization in nuts, cereals, and legumes. Journal of Agricultural and Food Chemistry, 61, 9148-9154.

Błaszczyk, A., Sady, S., \& Sielicka, M. (2019). The stilbene profile in edible berries. Phytochemistry Reviews, 18(1), 37-67.

Blekas, G., Vassilakis, C., Harizanis, C., Tsimidou, M., \& Boskou, D. G. (2002). Biophenols in table olives. Journal of Agricultural and Food Chemistry, 50, 3688-3692.

Boudjou, S., Oomah, B. D., Zaidi, F., \& Hosseinian, F. (2013). Phenolic content and antioxidant and anti-inflammatory activities of legume fractions. Food Chemistry, 138, 1543-1550.

Brahmachari, G. (2008). Naturally occurring flavanones: An overview. Natural Product Communications, 3(8), 1337-1354.

Braicu, C., Ladomery, M. R., Chedea, V. S., Irimie, A., \& Berindan-Neagoe, I. (2013). The relationship between the structure and biological actions of green tea catechins. Food Chemistry, 141, 3282-3289.

Buck, K., Zaineddin, A. K., Vrieling, A., Linseisen, J., \& Chang-Claude, J. (2010). Meta-analyses of lignans and enterolignans in relation to breast cancer risk. American Journal of Clinical Nutrition, 92(1), 141-153.
Bustamante-Rangel, M., Delgado-Zamarreño, M. M., Pérez-Martín, L., Rodríguez-Gonzalo, E., \& Domínguez-Álvarez, J. (2018). Analysis of isoflavones in foods. Comprehensive Reviews in Food Science and Food Safety, 17, 391-411.

Calderón-Montaño, J. M., Burgos-Morón, E., Pérez-Guerrero, C., \& LópezLázaro, M. (2011). A review on the dietary flavonoid kaempferol. MiniReviews in Medicinal Chemistry, 11(4), 298-344.

Campos-Vega, R., Reynoso-Camacho, R., Pedraza-Aboytes, G., AcostaGallegos, J. A., Guzman-Maldonado, S. H., Paredes-Lopez, O., ... Loarca-Piña, G. (2009). Chemical composition and in vitro polysaccharide fermentation of different beans (Phaseolus vulgaris L.). Journal of Food Science, 74, T59-T65.

Cantos, E., Tomas-Barberan, F. A., Martinez, A., \& Espin, J. C. (2003). Differential stilbene induction susceptibilty of 7 red wine grape varieties upon post-harvest UV-C irradiation. European Food Research and Technology, 217(3), 253-258.

Cao, W., Ye, L. H., Cao, J., Xu, J. J., Peng, L. Q., Zhu, Q. Y., ... Hu, S. S. (2015). Quantitative analysis of flavanones from citrus fruits by using mesoporous molecular sieve-based miniaturized solid phase extraction coupled to ultrahigh-performance liquid chromatography and quadrupole time-of-flight mass spectrometry. Journal of Chromatography A, 1406, 68-77.

Cao, Y., Himmeldirk, K. B., Qian, Y., Ren, Y., Malki, A., \& Chen, X. (2014). Biological and biomedical functions of penta-O-galloyl-D-glucose and its derivatives. Journal of natural Medicine, 68(3), 465-472.

Carmona, M., Sánchez, A. M., Ferreres, F., Zalacain, A., Tomas-Barberán, F. A., \& Alonso, G. L. (2007). Identification of the flavonoid fraction in saffron spice by LC/DAD/MS/MS: Comparative study of samples from different geographical origins. Food Chemistry, 100, 445-450.

Cassino, C., Tsolakis, C., Bonello, F., Gianotti, V., \& Osella, D. (2019). Wine evolution during bottle aging, studied by $1 \mathrm{H}$ NMR spectroscopy and multivariate statistical analysis. Food Research International, 116, 566-577.

Cermak, R., Durazzo, A., Maiani, G., Böhm, V., Kammerer, D. R., Carle, R., ... Galensa, R. (2009). The influence of postharvest processing and storage of foodstuffs on the bioavailability of flavonoids and phenolic acids. Molecular Nutrition \& Food Research, 53(Suppl 2), S184-S193.

Chandrasekara, A., \& Shahidi, F. (2010). Content of insoluble bound phenolics in millets and their contribution to antioxidant capacity. Journal of Agricultural and Food Chemistry, 58, 6706-6714.

Chang, S. K., Alasalvar, C., Bolling, B. W., \& Shahidi, F. (2017). Nuts and their co-products: The impact of processing (roasting) on phenolics, bioavailability, and health benefits a coprehensive review. Journal of Functional Foods Complete., 14, 103-109.

Chen, A. Y., \& Chen, Y. C. (2013). A review of the dietary flavonoid, kaempferol on human health and cancer chemoprevention. Food Chemistry, 138(4), 2099-2107.

Chen, M. H., Mcclung, A. M., \& Bergman, C. J. (2016). Concentrations of oligomers and polymers of proanthocyanidins in red and purple rice bran and their relationships to total phenolics, flavonoids, antioxidant capacity and whole grain color. Food Chemistry, 208, 279-287.

Chen, S., Jiang, H., Wu, X., \& Fang, J. (2016). Therapeutic effects of quercetin on inflammation, obesity, and type 2 diabetes. Mediators of Inflammation, 2016, 9340637.

Chen, X., Xiong, J., Huang, S., Li, X., Zhang, Y., Zhang, L., \& Wang, F. (2018). Analytical profiling of proanthocyanidins from Acacia mearnsii Bark and In vitro assessment of antioxidant and antidiabetic potential. Molecules, 23(11). pii: E2891

Cheynier, V., Comte, G., Davies, K. M., Lattanzio, V., \& Martens, S. (2013). Plant phenolics: Recent advances on their biosynthesis, genetics, and ecophysiology. Plant Physiology and Biochemistry, 72, 1-20. 
Chun, O. K., Smith, N., Sakagawa, A., \& Lee, C. Y. (2004). Antioxidant properties of raw and processed cabbages. International Journal of Food Science and Nutrition, 55, 191-199.

Clifford, M. N., Jaganath, I. B., Ludwig, I. A., \& Crozier, A. (2017). Chlorogenic acids and the acyl-quinic acids: Discovery, biosynthesis, bioavailability and bioactivity. Natural Product Report, 34(12), 1391-1421.

Colla, G., Rouphael, Y., Cardarelli, M., Svecova, E., Rea, E., \& Lucini, L. (2013). Effects of saline stress on mineral composition, phenolic acids and flavonoids in leaves of artichoke and cardoon genotypes grown in floating system. Journal of the Science of Food and Agriculture, 93, 1119-1127.

Corona, G., Ji, Y., Anegboonlap, P., Hotchkiss, S., Gill, C., Yaqoob, P., ... Rowland, I. (2016). Gastrointestinal modifications and bioavailability of brown seaweed phlorotannins and effects on inflammatory markers. British Journal of Nutrition, 115, 1240-1253.

Costa, C., Tsatsakis, A., Mamoulakis, C., Teodoro, M., Briguglio, G., Caruso, E., ... Fenga, C. (2017). Current evidence on the effect of dietary polyphenols intake on chronic diseases. Food Chemical Toxicology, 110, 286-299.

D'Evoli, L., Lucarini, M., del Pulgar, J. S., Aguzzi, A., Gabrielli, P., Gambelli, L., \& Lombardi-Boccia, G. (2016). Phenolic Acids Content and Nutritional Quality of Conventional, Organic and Biodynamic Cultivations of the Tomato CXD271BIO Breeding Line (Solanum lycopersicum L.). Food and Nutrition Sciences, 7, 1112-1121.

D'Evoli, L., Morroni, F., Lombardi-Boccia, G., Lucarini, M., Hrelia, P., Cantelli-Forti, G., \& Tarozzi, A. (2013). Red chicory (Cichorium intybus L. cultivar) as a potential source of antioxidant anthocyanins for intestinal health. Oxidative Medicine and Cellular Longevity, 2013, 704310.

Daliu, P., Santini, A., \& Novellino, E. (2019). From pharmaceuticals to nutraceuticals: Bridging disease prevention and management. Expert Review of Clinical Pharmacology, 12(1), 1-7.

Decroix, L., Soares, D. D., Meeusen, R., Heyman, E., \& Tonoli, C. (2018). Cocoa Flavanol Supplementation and exercise: A systematic review. Sports Medicine, 48(4), 867-892.

Desch, S., Schmidt, J., Kobler, D., Sonnabend, M., Eitel, I., Sareban, M., ... Thiele, H. (2010). Effect of cocoa products on blood pressure: Systematic review and meta-analysis. American Journal of Hypertension, 23(1), 97-103.

Devi, K. P., Malar, D. S., Nabavi, S. F., Sureda, A., Xiao, J., Nabavi, S. M., \& Daglia, M. (2015). Kaempferol and inflammation: From chemistry to medicine. Pharmacology Research, 99, 1-10. https://doi.org/10.1016/ j.phrs.2015.05.002

van Die, M. D., Bone, K. M., Williams, S. G., \& Pirotta, M. V. (2014). Soy and soy isoflavones in prostate cancer: A systematic review and metaanalysis of randomized controlled trials. BJU International, 113(5b), E119-E130.

Dueñas, M., Sarmento, T., Aguilera, Y., Benitez, V., Mollá, E., Esteban, R. M., \& Martín-Cabrejas, M. A. (2016). Impact of cooking and germination on phenolic composition and dietary fibre fractions in dark beans (Phaseolus vulgaris L.) and lentils (Lens culinaris L.). LWT-Food Science and Technology, 66, 72-78.

Durazzo, A. (2018a). Lignans. In M. L. N. Leo, \& A. G. U. Janet (Eds.), Phenolic compounds in food: Characterization and analysis (food analysis and properties). Boca Raton, FL, USA: CRC Press. Chapter 11

Durazzo, A. (2018b). Extractable and non-extractable polyphenols: An overview. In F. Saura-Calixto, \& J. Pérez-Jiménez (Eds.), Non-extractable polyphenols and carotenoids: Importance in human nutrition and health. Food Chem., Func. Anal. No. 5 (pp. 1-37). London, UK: Royal Society of Chemistry.
Durazzo, A., Azzini, E., Foddai, M. S., Nobili, F., Garaguso, I., Raguzzini, A., ... Maiani, G. (2010). Influence of different crop management practices on the nutritional properties and benefits of tomato Lycopersicon esculentum cv Perfectpeel. International Journal of Food Science and Technology, 45, 2637-2644.

Durazzo, A., Azzini, E., Lazzé, M. C., Raguzzini, A., Pizzala, R., Maiani, G., ... Maiani, G. (2014). Antioxidants in Italian head lettuce (Lactuca sativa var. capitata L.) grown in organic and conventional systems under greenhouse conditions. Journal of Food Biochemistry, 38, 56-61.

Durazzo, A., D'Addezio, L., Camilli, E., Piccinelli, R., Turrini, A., Marletta, L., ... Sette, S. (2018). From plant compounds to botanicals and back: A current snapshot. Molecules, 23(8), pii: E1844.

Durazzo, A., Lucarini, M., Camilli, E., Marconi, S., Gabrielli, P., Lisciani, S., ... Marletta, L. (2018). Dietary lignans: definition, description and research trends in databases development. Molecules, 23(12). pii: E3251

Durazzo, A., \& Lucarini, M. A. (2018). Current shot and re-thinking of antioxidant research strategy. Brazilian Journal of Analytical Chemistry, 5 , 9-11.

Durazzo, A., Turfani, V., Azzini, E., Maiani, G., \& Carcea, M. (2013). Phenols, lignans and antioxidant properties of legume and sweet chestnut flours. Food Chemistry, 140, 660-671.

eBASIS website. eBASIS-Bioactive Substances in Food Information System. Available online: http://ebasis.eurofir.org/Default.asp (accessed on 19 May 2019).

Ehala, S., Vaher, M., \& Kaljurand, M. (2005). Characterization of phenolic profiles of Northern European berries by capillary electrophoresis and determination of their antioxidant activity. Journal of Agricultural and Food Chemistry, 53, 6484-6490.

El Gharras, H. (2009). Polyphenols: Food sources, properties and applications. A review. International Journal of Food Science and Technology, 44(12), 2512-2518.

El Khawand, T., Courtois, A., Valls, J., Richard, T., \& Krisa, S. (2018) A review of dietary stilbenes: Sources and bioavailability. Phytochemistry Reviews, 17, 1007-1029. https://doi.org/10.1007/s11101-0189578-9

El-Seedi, H. R., El-Said, A. M., Khalifa, S. A., Göransson, U., Bohlin, L., BorgKarlson, A. K., \& Verpoorte, R. (2012). Biosynthesis, natural sources, dietary intake, pharmacokinetic properties, and biological activities of hydroxycinnamic acids. Journal of Agricultural and Food Chemistry, 60(44), 10877-10895.

Erices, J. I., Torres, Á., Niechi, I., Bernales, I., \& Quezada, C. (2018). Current natural therapies in the treatment against glioblastoma. Phytotherapy Research, 32(11), 2191-2201.

Farhadi, F., Khameneh, B., Iranshahi, M., \& Iranshahy, M. (2018). Antibacterial activity of flavonoids and their structure-activity relationship: An update review. Phytotherapy Research, 33(1), 13-40. https://doi.org/ 10.1002/ptr.6208

Farhat, G., Drummond, S., \& Al-Dujaili, E. A. S. (2017). Polyphenols and their role in obesity management: A systematic review of randomized clinical trials. Phytotherapy Research, 31(7), 1005-1018.

Feringa, H. H., Laskey, D. A., Dickson, J. E., \& Coleman, C. I. (2011). The effect of grape seed extract on cardiovascular risk markers: A metaanalysis of randomized controlled trials. Journal of American Dietetic Association, 111, 1173-1181.

Finicelli, M., Squillaro, T., Di Cristo, F., Di Salle, A., Melone, M. A. B., Galderisi, U., \& Peluso, G. (2019). Metabolic syndrome, Mediterranean diet, and polyphenols: Evidence and perspectives. Journal of Cellular Physiology, 234(5), 5807-5826. https://doi.org/10.1002/jcp.27506

Fischer, U. A., Jaksch, A. V., Carle, R., \& Kammerer, D. R. (2013). Influence of origin source, different fruit tissue and juice extraction methods on 
anthocyanin, phenolic acid, hydrolyzable tannin and isolariciresinol contents of pomegranate (Punica granatum L.) fruits and juices. European Food Research and Technology, 237, 209-221.

Fotland, T. Ø., Paulsen, J. E., Sanner, T., Alexander, J., \& Husøy, T. (2012). Risk assessment of coumarin using the benchmark dose (BMD) approach: Children in Norway which regularly eat oatmeal porridge with cinnamon may exceed the TDI for coumarin with several folds. Food and Chemical Toxicology, 50(3-4), 903-912.

Franco, O. H., Chowdhury, R., Troup, J., Voortman, T., Kunutsor, S., Kavousi, M., ... Muka, T. (2016). Use of plant-based therapies and menopausal symptoms: A systematic review and meta-analysis. JAMA, 315, 2554-2563.

Franke, A. A., Custer, L. J., Arakaki, C., \& Murphy, S. P. (2004). Vitamin C and flavonoid levels of fruits and vegetables consumed in Hawaii. Journal of Food Composition and Analysis, 17, 1-35.

Fritz, H., Seely, D., Flower, G., Skidmore, B., Fernandes, R., Vadeboncoeur, S., ... Fergusson, D. (2013). Soy, red clover, and isoflavones and breast cancer: A systematic review. PLoS ONE, 8(11), e81968. https://doi.org/ 10.1371/journal.pone.0081968

Fuentes, E., \& Palomo, I. (2014). Mechanisms of endothelial cell protection by hydroxycinnamic acids. Vascular Pharmacology, 63(3), 155-161.

Gadkari, P. V., \& Balaraman, M. (2015). Catechins: Sources, extraction and encapsulation: A review. Food and Bioproducts Processing, 93, 122-138.

Genovese, S., \& Epifano, F. (2011). Auraptene: a natural biologically active compound with multiple targets. Current Drug Targets, 12(3), 381-386.

Giuffrida, D., Salvo, F., Ziino, M., Toscano, G., \& Dugo, G. (2002). Initial investigation on some chemical constituents of capers (Capparis Spinosa L.) from the island of Salina. Italian Journal of Food Science, 14(1), 25-33.

González-Laredo, R. F., Rocha-Guzmán, N. E., Gallegos-Infante, J. A., Moreno-Jiménez, M. R., \& Gómez, C. I. (2018). Stilbenes in Foods. In M. L. N. Leo, \& A. G. U. Janet (Eds.), Phenolic Compounds in Food: Characterization and Analysis (Food Analysis and Properties). Boca Raton, FL, USA: CRC Press. Chapter: 8

Grosso, G., Godos, J., Lamuela-Raventos, R., Ray, S., Micek, A., Pajak, A., .. Galvano, F. (2017). A comprehensive meta-analysis on dietary flavonoid and lignan intake and cancer risk: Level of evidence and limitations. Molecular Nutrition and Food Research, 61(4). https://doi. org/10.1002/mnfr.201600930

Grosso, G., Micek, A., Godos, J., Pajak, A., Sciacca, S., Galvano, F., \& Giovannucci, E. L. (2017). Dietary flavonoid and lignan intake and mortality in prospective cohort studies: Systematic review and doseresponse meta-analysis. American Journal of Epidemiology, 185(12), 1304-1316.

Grosso, G., Stepaniak, U., Micek, A., Kozela, M., Stefler, D., Bobak, M., \& Pajak, A. (2017). Dietary polyphenol intake and risk of type 2 diabetes in the Polish arm of the Health, Alcohol and Psychosocial factors in Eastern Europe (HAPIEE) study. British Journal of Nutrition, 118(1), 60-68.

Grosso, G., Stepaniak, U., Micek, A., Kozela, M., Stefler, D., Bobak, M., \& Pajak, A. (2018). Dietary polyphenol intake and risk of hypertension in the Polish arm of the HAPIEE study. European Journal of Nutrition, 57(4), 1535-1544.

Gu, L., House, S. E., Wu, X., Ou, B., \& Prior, R. L. (2006). Procyanidin and catechin contents and antioxidant capacity of cocoa and chocolate products. Journal of Agricultural and Food Chemistry, 54, 4057-4061.

Guedon, D. J., \& Pasquier, B. P. (1994). Analysis and distribution of flavonoid glycosides and rosmarinic acid in 40 Mentha $x$ piperita clones. Journal of Agricultural and Food Chemistry, 42, 679-684.
Guo, X., Tresserra-Rimbau, A., Estruch, R., Martínez-González, M. A., Medina-Remón, A., Fitó, M., ... Lamuela-Raventós, R. M. (2017). Polyphenol levels are inversely correlated with body weight and obesity in an elderly population after 5 years of follow up (The Randomised PREDIMED Study). Nutrients, 9(5), pii: E452). https://doi.org/ $10.3390 /$ nu9050452

Guo, X., Yang, B., Tan, J., Jiang, J., \& Li, D. (2016). Associations of dietary intakes of anthocyanins and berry fruits with risk of type 2 diabetes mellitus: A systematic review and meta-analysis of prospective cohort studies. European Journal of Clinical Nutrition, 70, 1360-1367.

Gutiérrez-Grijalva, E. P., Ambriz-Pére, D. L., Leyva-López, N., CastilloLópez, R. I., \& Heredia, J. B. (2016). Review: Dietary phenolic compounds, health benefits and bioaccessibility. Archivos Latinoamericanos de Nutrición, 66(2), 87-100.

Gutierrez-Orozco, F., \& Failla, M. L. (2013). Biological activities and bioavailability of mangosteen xanthones: A critical review of the current evidence. Nutrients, 5, 3163-3183.

Harnly, J. M., Doherty, R. F., Beecher, G. R., Holden, J. M., Haytowitz, D., Bhagwat, S., \& Gebhardt, S. (2006). Flavonoid content of U.S. fruits, vegetables, and nuts. Journal of Agricultural and Food Chemistry, 54, 9966-9977.

Hassan, M. O., Saleh, A. M., \& AbdElgawad, H. (2018). Sonchus oleraceus residue improves nutritive and health-promoting value of common bean (Phaseolus vulgaris L.): a metabolic Study. Journal of Agricultural and Food Chemistry, 66, 2092-2100.

Haytowitz, D., Wu, X., \& Bhagwat, S. (2018a). USDA Database for the Proanthocyanidin Content of Selected Foods Release 2.1. U.S. Department of Agriculture, Agricultural Service. Nutrient Data Laboratory Home Page: Retrieved from http://www.ars.usda.gov/nutrientdata/ flav (accessed on 19 May 2019).

Haytowitz, D. B., Wu, X., \& Bhagwat, S. (2018b). USDA Database for the Flavonoid Content of Selected Foods, Release 3.3. U.S. Department of Agriculture, Agricultural Research Service. Nutrient Data Laboratory Home Page: http://www.ars.usda.gov/nutrientdata/flav (accessed on 21 May 2019)

Hellström, J. K., \& Mattila, P. H. (2008). HPLC determination of extractable and unextractable proanthocyanidins in plant materials. Journal of Agricultural and Food Chemistry, 56, 7617-7624.

Hirpara, K. V., Aggarwal, P., Mukherjee, A. J., Joshi, N. J., \& Burman, A. C. (2009). Quercetin and its derivatives: Synthesis, pharmacological uses with special emphasis on anti-tumor properties and prodrug with enhanced bioavailability. Anti-Cancer Agents in Medicinal Chemistry, 9(2), 138-161.

Hoerger, C. C., Praplan, A. P., Becker, L., Wettstein, F. E., Hungerbuhler, K., \& Bucheli, T. D. (2011). Quantification of Five Isoflavones and Coumestrol in Various Solid Agroenvironmental Matrices Using ${ }^{13}$ C3Labeled Internal Standards. Journal of Agricultural and Food Chemistry, 59, 847-856.

Hoffmann-Ribani, R., Huber, L. S., \& Rodriguez-Amaya, D. B. (2009). Flavonols in fresh and processed Brazilian fruits. Journal of Food Composition and Analysis, 22(4), 263-268.

Hostetler, G. L., Ralston, R. A., \& Schwartz, S. J. (2017). Flavones: Food sources, bioavailability, metabolism, and bioactivity. Advances in Nutrition, 8, 423-435.

Huber, L. S., Hoffman-Ribani, R., \& Rodriguez-Amaya, D. B. (2009). Quantitative variation in Brazilian vegetable sources of flavonols and flavones. Food Chemistry, 113, 1278-1282.

Hügel, H. M., Jackson, N., May, B., Zhang, A. L., \& Xue, C. C. (2016). Polyphenol protection and treatment of hypertension. Phytomedicine, 23(2), 220-231. 
Hussain, P. R., Chatterjee, S., Variyar, P. S., Sharma, A., Dar, M. A., \& Wani, A. M. (2013). Bioactive compounds and antioxidant activity of gamma irradiated sun dried apricots (Prunus armeniaca L.). Journal of Food Composition and Analysis, 30, 59-66.

Imai, T., Nomura, M., \& Fukushima, K. (2006). Evidence for involvement of the phenylpropanoid pathway in the biosynthesis of the norlignan agatharesinol. Journal of Plant Physiology, 163, 483-487.

Imran, M., Rauf, A., Shah, Z. A., Saeed, F., Imran, A., Arshad, M. U., ... Mubarak, M. S. (2019). Chemo-preventive and therapeutic effect of the dietary flavonoid kaempferol: A comprehensive review. Phytotherapy Research, 33, 263-275.

Inocencio, C., Rivera, D., Alcaraz, F., \& Tomás-Barberán, F. A. (2000). Flavonoid content of commercial capers (Capparis spinosa, C. sicula and C. orientalis) produced in Mediterranean countries. European Food Research and Technology, 212, 70-74.

Iriti, M., Kubina, R., Cochis, A., Sorrentino, R., Varoni, E. M., Kabała-Dzik, A., ... Wojtyczka, R. D. (2017). Rutin, a quercetin glycoside, restores chemosensitivity in human breast cancer cells. Phytotherapy Research, 31(10), 1529-1538. https://doi.org/10.1002/ptr.5878

Ivey, K. L., Lewis, J. R., Lim, W. H., Lim, E. M., Hodgson, J. M., \& Prince, R. L. (2013). Associations of proanthocyanidin intake with renal function and clinical outcomes in elderly. PLoS ONE, 8(8), e71166.

Justesen, U., \& Knuthsen, P. (2001). Composition of flavonoids in fresh herbs and calculation of flavonoid intake by use of herbs in traditional Danish dishes. Food Chemistry, 73, 245-250.

Justesen, U., Knuthsen, P., \& Leth, T. (1998). Quantitative analysis of flavonols, flavones, and flavonones in fruits, vegetables and beverages by high-performance liquid chromatography with photo-diode array and mass spectrometric detection. Journal of Chromatography A, 799, 101-110.

Kabera, J. N., Semana, E., Mussa, A. R., \& He, X. (2014). Plant secondary metabolites: Biosynthesis, classification, function and pharmacological properties. Journal of Pharmacy and Pharmacology, 2, 377-392.

Kalili, K. M., Vestner, J., Stander, M. A., \& de Villiers, A. (2013). Toward unraveling grape tannin composition: Application of online hydrophilic interaction chromatography $\mathrm{x}$ reversed-phase liquid chromatographytime-of-flight mass spectrometry of grape seed analysis. Analytical Chemistry, 85, 9107-9115.

Kent, K., Charlton, K. E., Netzel, M., \& Fanning, K. (2017). Food-based anthocyanin intake and cognitive outcomes in human intervention trials: A systematic review. Journal of Human Nutrition and Dietetics, 30(3), 260-274.

Khadem, S., \& Marles, R. J. (2010). Monocyclic phenolic acids; hydroxyand polyhydroxybenzoic acids: Occurrence and recent bioactivity studies. Molecules, 15(11), 7985-8005.

Khan, M. K., Huma, Z. E., \& Dangles, O. (2014). A comprehensive review on flavanones, the major citrus polyphenols. Journal of Food Composition and Analysis, 33, 85-104.

Khoddami, A., Wilkes, A. M., \& Roberts, H. T. (2013). Techniques for analysis of plant phenolic compounds. Molecules, 18, 2328-2375.

Kiely, M., Black, L. J., Plumb, J., Kroon, P. A., Hollman, P. C., Larsen, J. C., ... Finglas, P. (2010). EuroFIR consortium. EuroFIR eBASIS: Application for health claims submissions and evaluations. European Journal of Clinical Nutrition, 3, S101.

Kimble, R., Keane, K. M., Lodge, J. K., \& Howatson, G. (2018). Dietary intake of anthocyanins and risk of cardiovascular disease: A systematic review and meta-analysis of prospective cohort studies. Critical Review in Food Science and Nutrition, 2, 1-12.
Kocaadam, B., \& Şanlier, N. (2017). Curcumin, an active component of turmeric (Curcuma longa), and its effects on health. Critical Reviews in Food Science and Nutrition, 57, 2889-2895.

Kofink, M., Papagiannopoulos, M., \& Galensa, R. (2007). (-)Catechin in cocoa and chocolate: Occurrence and analysis of an atypical flavan-3ol enantiomer. Molecules, 12, 1274-1288.

Konar, N., Poyrazoglu, E. S., Demir, K., \& Artik, N. (2012). Effect of different sample preparation methods on isoflavone, lignan, coumestan and flavonoid contents of various vegetables determined by triple quadrupole LC-MS/MS. Journal of Food Composition and Analysis, 26, 26-35.

Koushki, M., Amiri-Dashatan, N., Ahmadi, N., Abbaszadeh, H. A., \& RezaeiTavirani, M. (2018). Resveratrol: A miraculous natural compound for diseases treatment. Food Science and Nutrition, 6(8), 2473-2490.

Kressler, J., Millard-Stafford, M., \& Warren, G. L. (2011). Quercetin and endurance exercise capacity: A systematic review and meta-analysis. Medicine \& Science in Sports \& Exercise, 43(12), 2396-2404.

Kuhnle, G. G. C., Dell'Aquila, C., Aspinall, S. M., Runswick, S. A., Joosen, A. M. C. P., Mulligan, A. A., \& Bingham, S. A. (2009). Phytoestrogen content of fruits and vegetables commonly consumed in the UK based on LC-MS and 13C-labelled standards. Food Chemistry, 116, 542-554.

Kumar, S., \& Pandey, A. K. (2013). Chemistry and biological activities of flavonoids: An overview. Scientific World Journal, 2013, 162750.

Kunnumakkara, A. B., Bordoloi, D., Padmavathi, G., Monisha, J., Roy, N. K., Prasad, S., \& Aggarwal, B. B. (2017). Curcumin, the golden nutraceutical: Multitargeting for multiple chronic diseases. British Journal of Pharmacology, 174, 1325-1348.

Lafay, S., \& Gil-Izquierdo, A. (2008). Bioavailability of phenolic acids. Phytochemistry Reviews, 7, 301-311.

Lambert, J. D., Lee, M. J., Lu, H., Meng, X., Ju, J., Hong, J., ... Yang, C. S. (2003). Epigallocatechin-3-gallate is absorbed but extensively glucuronidated. Journal of Nutrition, 13, 3262S-3267S.

Lamikanra, O., Grimm, C. C., Rodin, J. B., \& Inyang, I. D. (1996). Hydroxylated stilbenes in selected American wines. Journal of Agricultural and Food Chemistry, 44, 1111-1115.

Lempereur, I., Rouau, X., \& Abecassis, J. (1997). Genetic and agronomic variation in arabinoxylan and ferulic acid contents of durum wheat (Triticum durum L.) grain and its milling fractions. Journal of Cereal Science, 25, 103-110.

Lewis, N. G., \& Davin, L. B. (1999). Lignans: Biosynthesis and function. In D. Barton, K. Nakanishi, O. Meth-Cohn, \& U. Sankawa (Eds.), Comprehensive natural products chemistry. Polyketides and other secondary metabolites including fatty acids and their derivatives (pp. 639-712). Amsterdam, Netherlands: Elsevier.

Leyton, A., Pezoa-Conte, R., Barriga, A., Buschmann, A. H., Mäki-Arvela, P., Mikkola, J. P., \& Lienqueo, M. E. (2016). Identification and efficient extraction method of phlorotannins from the brown seaweed Macrocystis pyrifera using an orthogonal experimental design. Algal Research, 16, 201-208.

Li, G., Thomas, S., \& Johnson, J. J. (2013). Polyphenols from the mangosteen (Garcinia mangostana) fruit for breast and prostate cancer. Frontiers Pharmacology, 4, 1-4.

Li, L., Zhang, L., \& Du, G. H. (2018). Quercetin. In book: Natural Small Molecule Drugs from Plants (pp. 725-729). Singapore: Ed. Springer. https:// doi.org/10.1007/978-981-10-8022-7_118

Li, S. H., Zhao, P., Tian, H. B., Chen, L. H., \& Cui, L. Q. (2015). Effect of grape polyphenols on blood pressure: A meta-analysis of randomized controlled trials. PLOS ONE, 10(9), e0137665. 
Lin, B. W., Gong, C. C., Song, H. F., \& Cui, Y. Y. (2017). Effects of anthocyanins on the prevention and treatment of cancer. British Journal of Pharmacology, 174, 1226-1243.

Lin, L. Z., Mukhopadhayay, S., Robbins, R. J., \& Harnly, J. M. (2007). Identification and quantification of flavonoids of Mexican oregano (Lippia graveolens) by LC-DAD-ESI/MS analysis. Journal of Food Composition and Analysis, 20, 361-369.

Lin, X., Zhang, I., Li, A., Manson, J. E., Sesso, H. D., Wang, L., \& Liu, S. (2016). Cocoa flavanol intake and biomarkers for cardiometabolic health: A systematic review and meta-analysis of randomized controlled trials. Journal of Nutrition, 146(11), 2325-2333.

Liobikas, J., Skemiene, K., Trumbeckaite, S., \& Borutaite, V. (2016). Anthocyanins in cardioprotection: A path through mitochondria. Pharmacology Research, 113(PtB), 808-815.

Liu, C., Sun, J., Lu, Y., \& Bo, Y. (2016). Effects of anthocyanin on serum lipids in dyslipidemia patients: A systematic review and metaAnalysis. PLoS ONE, 11, e0162089.

Lugasi, A., \& Hovari, J. (2000). Flavonoid aglycons in foods of plant origin I. Vegetables. Acta Alimentaria, 29, 345-352.

Ma, H., Liu, W., Frost, L., Wang, L., Kong, L., Dain, J. A., \& Seeram, N. P. (2015). The hydrolyzable gallotannin, penta-O-galloyl- $\beta$-Dglucopyranoside, inhibits the formation of advanced glycation endproducts by protecting protein structure. Molecular Byosystems, 11(5), 1338-1347.

Mantzorou, M., Pavlidou, E., Vasios, G., Tsagalioti, E., \& Giaginis, C. (2018). Effects of curcumin consumption on human chronic diseases: A narrative review of the most recent clinical data. Phytotherapy Research, 32(6), 957-975.

Martinez, M. L., Fabani, M. P., Baroni, M. V., Huaman, R. N. M., Ighani, M., Maestri, D. M., ... Feresin, G. E. (2016). Argentinian pistachio oil and flour: A potential novel approach of pistachio nut utilization. Journal of Food Science and Technology-Mysore, 53, 2260-2269.

Martínez-Sánchez, A., Gil-Izquierdo, A., Gil, M. I., \& Ferreres, F. (2008). A comparative study of flavonoid compounds, vitamin $\mathrm{C}$, and antioxidantproperties of baby leaf Brassicaceae species. Journal of Agricultural and Food Chemistry, 56, 2330-2340.

Maru, G. B., Hudlikar, R. R., Kumar, G., Gandhi, K., \& Mahimkar, M. B. (2016). Understanding the molecular mechanisms of cancer prevention by dietary phytochemicals: From experimental models to clinical trials. World Journal of Biological Chemistry, 7(1), 88-99.

Mattila, P., Astola, J., \& Kumpulainen, J. (2000). Determination of flavonoids in plant material by HPLC with diode-array andelectro-array detection. Journal of Agricultural and Food Chemistry, 48, 5834-5841.

Mazur, W., Fotsis, T., Wahala, K., Ojala, S., Salakka, A., \& Adlercreutz, H. (1996). Isotope dilution gas chromatographic-mass spectrometric method for the determination of isoflavonoids, coumestrol, and lignans in food samples. Analytical Biochemistry, 233, 169-180.

Medina-Remón, A., Casas, R., Tressserra-Rimbau, A., Ros, E., MartínezGonzález, M. A., Fitó, M., ... PREDIMED Study Investigators (2017). Polyphenol intake from a Mediterranean diet decreases inflammatory biomarkers related to atherosclerosis: A substudy of the PREDIMED trial. British Journal Clinical Pharmacology, 83(1), 114-128.

Medina-Remón, A., Zamora-Ros, R., Rotchés-Ribalta, M., Andres-Lacueva, C., Martínez-González, M. A., Covas, M. I., ... PREDIMED Study Investigators. (2011). Total polyphenol excretion and blood pressure in subjects at high cardiovascular risk. Nutrition, Metabolism, and Cardiovascular Diseases:NMCD, 21(5),323-331.

Miccadei, S., Di Venere, D., Cardinali, A., Romano, R., Durazzo, A., Foddai, M. S., ... Maiani, G. (2008). Antioxidative and apoptotic properties of polyphenolic extracts from edible part of artichoke (Cynara scolymus
L.) on cultured rat hepatocytes and on human hepatoma cells. Nutrition and Cancer, 60(2), 276-283.

Milani, A., Basirnejad, M., Shahbazi, S., \& Bolhassani, A. (2017). Carotenoids: Biochemistry, pharmacology and treatment. British Journal of Pharmacology, 174, 1290-1324.

Milder, I. E. J., Arts, I. C. W., van de Putte, B., Venema, D. P., \& Hollman, P. C. H. (2005). Lignan contents of Dutch plant foods: A database including lariciresinol, pinoresinol, secoisolariciresinol and matairesinol. Bristish Journal of Nutrition, 93, 393-402.

Mileo, A. M., \& Miccadei, S. (2016). Polyphenols as modulator of oxidative stress in cancer disease: New therapeutic strategies. Oxidative Medicine and Cellular Longevity, 2016. Article ID 6475624, 17 pages

Miltonprabu, S., Tomczyk, M., Skalicka-Woźniak, K., Rastrelli, L., Daglia, M., Nabavi, S. F., ... Nabavi, S. M. (2017). Hepatoprotective effect of quercetin: From chemistry to medicine. Food and Chemical Toxicology, 108(Pt B), 365-374.

Miranda, A. M., Steluti, J., Fisberg, R. M., \& Marchioni, D. M. (2016). Association between polyphenol intake and hypertension in adults and older adults: A population-based study in Brazil. PLoS ONE, 11(10), e0165791.

Miura, T., Ichiki, H., Hashimoto, I., Iwamoto, N., Kao, M., Kubo, M., ... Tanigawa, K. (2001). Antidiabetic activity of a xanthone compound, mangiferin. Phytomedicine, 8, 85-87. https://doi.org/10.1078/09447113-00009

Mohammadi, V., Dehghani, S., Larijani, B., \& Azadbakht, L. (2016). Ovarian cancer risk and nonisoflavone flavonoids intake: A systematic review of epidemiological studies. Journal of Research in Medical Sciences, 21, 123.

Nakmareong, S., Kukongviriyapan, U., Pakdeechote, P., Donpunha, W., Kukongviriyapan, V., Kongyingyoes, B., ... Phisalaphong, C. (2011). Antioxidant and vascular protective effects of curcumin and tetrahydrocurcumin in rats with L-NAME-induced hypertension. Naunyn Schmiedebergs Archives of Pharmacology, 383(5), 19-29.

Negi, J. S., Bisht, V. K., Singh, P., Rawat, S. M., \& Joshi, G. P. (2013). Naturally occurring xanthones: Chemistry and biology. Journal of Applied Chemistry, 2013. Article ID 621459, 9 pages

Nelson, K. M., Dahlin, J. L., Bisson, J., Graham, J., Pauli, G. F., \& Walters, M. A. (2017). The essential medicinal chemistry of curcumin. Journal of Medicinal Chemistry, 60(5), 1620-1637.

Neveu, V., Perez-Jiménez, J., Vos, F., Mennen, L., Knox, C., Eisner, R., ... Scalbert, A. (2010). Phenol-Explorer: An online comprehensive database on polyphenol contents in foods. Database, 2010, bap024.

Ninfali, P., Antonini, E., Frati, A., \& Scarpa, E. S. (2017). C-Glycosyl flavonoids from Beta vulgaris vicla and betalains from Beta vulgaris rubra: Antioxidant, anticancer and antiinflammatory activities-a review. Phytotherapy Research, 31(6), 871-884.

Noad, R. L., Rooney, C., McCall, D., Young, I. S., McCance, D., McKinley, M. C., ... McKeown, P. P. (2016). Beneficial effect of a polyphenol-rich diet on cardiovascular risk: A randomised control trial. Heart (British Cardiac Society), 102(17), 1371-1379.

Obermeyer, W. R., Musser, S. M., Betz, J. M., Casey, R. E., Pohland, A. E., \& Page, S. W. (1995). Chemical studies of phytoestrogens and related compounds in dietary supplements: Flax and chaparral. Proceedings of the Society for Experimental Biology and Medicine, 208, 6-12.

Oboh, G., Ademosun, A. O., \& Ogunsuyi, O. B. (2016). Quercetin and its role in chronic diseases. In S. Gupta, S. Prasad, \& B. Aggarwal (Eds.), Drug Discovery from Mother Nature (Vol. 929). Springer International Publishing: Basel, Switzerland. Advances in Experimental Medicine and Biology. (pp. 377-387).

Oppenheimer, A. (1937). Turmeric (curcumin) in biliary disease. The Lancet, 229, P619-P621. 
Orhan, I. E., Nabavi, S. F., Daglia, M., Tenore, G. C., Mansouri, K., \& Nabavi, S. M. (2015). Naringenin and atherosclerosis: A review of literature. Current Pharmacology Biotechnology, 16(3), 245-251.

Owen, R. W., Haubner, R., Mier, W., Giacosa, A., Hull, W. E., Spiegelhalder, B., \& Bartsch, H. (2003). Isolation, structure elucidation and antioxidant potential of the major phenolic and flavonoid compounds in brined olive drupes. Food and Chemical Toxicolology, 41, 703-717.

Oyenihi, A. B., \& Smith, C. (2019). Are polyphenol antioxidants at the root of medicinal plant anti-cancer success? Journal of Ethnopharmacology, $229,54-72$.

Pagano, E., Romano, B., Izzo, A. A., \& Borrelli, F. (2018). The clinical efficacy of curcumin-containing nutraceuticals: An overview of systematic reviews. Pharmacological Research, 134, 79-91.

Parejo, I., Viladomat, F., Bastida, J., \& Codina, C. (2004). Development and validation of a high-performance liquid chromatographic method for the analysis of antioxidative phenolic compounds in fennel using a narrow bore reversed phase C18 column. Analytica Chimica Acta, 512, 271-278. https://doi.org/10.1016/j.aca.2004.02.053

Pascual-Theresa, S., \& Sanchez-Ballesta, M. T. (2008). Anthocyanins: From plant to health. Phytochemistry Reviews, 7, 281-299.

Pavlović, A., Dabić, D., Momirović, N., Dojčinović, B., Milojković-Opsenica, D., Tešić, Z., \& Natić, M. (2013). Chemical composition of two different extracts of berries harvested in Serbia. Journal of Agricultural and Food Chemistry, 61, 4188-4194.

Pei, K., Ou, J., Huang, J., \& Ou, S. (2016). p-coumaric acid and its conjugates: Dietary sources, pharmacokinetic properties and biological activities. Journal of Food Science and Agriculture, 96, 2952-2962.

Peluso, I., \& Serafini, M. (2017). Antioxidants from black and green tea: From dietary modulation of oxidative stress to pharmacological mechanisms. British Journal of Pharmacology, 174, 1195-1208.

Penalvo, J. L., Haajanen, K. M., Botting, N., \& Adlercreutz, H. (2005). Quantification of lignans in food using isotope dilution gas chromatography/mass spectrometry. Journal of Agricultural and Food Chemistry, 53, 9342-9347.

Pereira, D. M., Valentão, P., Pereira, J. A., \& Andrade, P. B. (2009). Phenolics: From chemistry to biology. Molecules, 14, 2202-2211.

Pervaiz, T., Songtao, J., Faghihi, F., Haider, M. S., \& Fang, J. (2017) Naturally occurring Anthocyanin, structure, functions and biosynthetic pathway in fruit plants. Journal of Plant Biochemistry \& Physiology, 5 , 187.

Plumb, J., Pigat, S., Bompola, F., Cushen, M., Pinchen, H., Nørby, E., ... Finglas, P. (2017). eBASIS (Bioactive Substances in Food Information Systems) and bioactive intakes: Major updates of the bioactive compound composition and beneficial bioeffects database and the development of a probabilistic model to assess intakes in Europe. Nutrients, 9, 320 .

Praud, D., Parpinel, M., Guercio, V., Bosetti, C., Serraino, D., Facchini, G., ... Rossi, M. (2018). Proanthocyanidins and the risk of prostate cancer in Italy. Cancer Causes \& Control, 29(2), 261-268.

Preinerstorfer, B., \& Sontag, G. (2004). Determination of isoflavones in commercial soy products by HPLC and coulometric electrode array detection. European Food Research and Technology, 219, 305-310.

Proestos, C., Koutelidakis, A. E., Kapsokefalou, M., \& Komaitis, M. (2011). Fruits and vegetables: a rich source of phenolic acids. In S. MunnéBosch (Ed.), Phenolic acids: Composition, applications, and health benefits (pp. 1-13). Hauppauge, N.Y., United States: Nova Science Publishers.

Rajendran, P., Rengarajan, T., Nandakumar, N., Palaniswami, R., Nishigaki, Y., \& Nishigaki, I. (2014). Kaempferol, a potential cytostatic and cure for inflammatory disorders. European Journal of Medicinal Chemistry, 86, 103-112.
Ramírez-Garza, S. L., Laveriano-Santos, E. P., Marhuenda-Muñoz, M., Storniolo, C. E., Tresserra-Rimbau, A., Vallverdú-Queralt, A., \& Lamuela-Raventós, R. M. (2018). Health effects of resveratrol: Results from human intervention trials. Nutrients, 10(12). pii: E1892

Ranka, S., Gee, J. M., Biro, L., Brett, G., Saha, S., Kroon, P., ... Johnson, I. T. (2008). Development of a food frequency questionnaire for the assessment of quercetin and naringenin intake. European Journal of Clinical Nutrition, 62(9), 1131-1138.

Rasouli, H., Mohammad-Bagher Hosseini-Ghazvini, S., \& Khodarahmi, R. (2018). Chapter 3: Therapeutic potentials of the most studied flavonoids: Highlighting antibacterial and antidiabetic functionalities. Studies in Natural Products Chemistry, 60, 85-118.

Rauf, A., Imran, M., Khan, I. A., Ur-Rehman, M., Gilani, S. A., Mehmood, Z., \& Mubarak, M. S. (2018). Anticancer potential of quercetin: A comprehensive review. Phytotherapy Research, 32(11), 2109-2130.

Rees, A., Dodd, G. F., \& Spencer, J. P. E. (2018). The Effects of flavonoids on cardiovascular health: A review of human intervention trials and implications for cerebrovascular function. Nutrients, 10(12). pii: E1852

Reinisalo, M., Kårlund, A., Koskela, A., Kaarniranta, K., \& Karjalainen, R. O. (2015). Polyphenol stilbenes: molecular mechanisms of defence against oxidative stress and aging-related diseases. Oxidative Medicine and Cellular Longevity, 2015, 340520.

Reis, J., Gaspar, A., Milhazes, N., \& Borges, F. (2017). Chromone as a privileged scaffold in drug discovery: recent advances. Journal of Medicinal Chemistry, 60(19), 7941-7957.

Rengasamy, K. R. R., Khan, H., Gowrishankar, S., Lagoa, R. J. L., Mahomoodally, F. M., Khan, Z., ... Pandian, S. K. (2019). The role of flavonoids in autoimmune diseases: Therapeutic updates. Pharmacology Therapy, 194, 107-131.

Riccio, G., Sommella, E., Badolati, N., Salviati, E., Bottone, S., Campiglia, P. ... Novellino, E. (2018). Annurca apple polyphenols protect murine hair follicles from taxane induced dystrophy and hijacks polyunsaturated fatty acid metabolism toward $\beta$-oxidation. Nutrients, 10(11). pii: E1808

Ried, K., Fakler, P., \& Stocks, N. P. (2017). Effect of cocoa on blood pressure. Cochrane Database System Review, 4, CD008893.

Rienks, J., Barbaresko, J., \& Nöthlings, U. (2017). Association of polyphenol biomarkers with risk of cardiovascular disease: A systematic review and meta-analysis of prospective cohort studies. Critical Review in Food Science and Nutrition, 2, 1-12.

Rienks, J., Barbaresko, J., Oluwagbemigun, K., Schmid, M., \& Nöthlings, U. (2018). Polyphenol exposure and risk of type 2 diabetes: Doseresponse meta-analyses and systematic review of prospective cohort studies. American Journal of Clinical Nutrition, 108(1), 49-61.

Roche, A., Ross, E., Walsh, N., O'Donnell, K., Williams, A., Klapp, M., ... Edelstein, S. (2017). Representative literature on the phytonutrients category: Phenolic acids. Critical Review of Food Science and Nutrition, 57(6), 1089-1096.

Rochlani, Y., Pothineni, N. V., Kovelamudi, S., \& Mehta, J. L. (2017). Metabolic syndrome: Pathophysiology, management, and modulation by natural compounds. Therapeutic Advances in Cardiovascular Disease, 11(8), 215-225.

Rodríguez-Carrasco, Y., Gaspari, A., Graziani, G., Santini, A., \& Ritieni, A. (2018). Fast analysis of polyphenols and alkaloids in cocoa-based products by ultra-high performance liquid chromatography and Orbitrap high resolution mass spectrometry (UHPLC-Q-Orbitrap-MS/MS). Food Research International, 111, 229-236.

Roessner, U., \& Beckles, D. M. (2009). Metabolite measurements. In J. Schwender (Ed.), Plant Metabolic Networks (pp. 39-69). New York, NY, USA: Springer Verlag. 
Romani, A., Mulinacci, N., Pinelli, P., Vincieri, F. F., \& Cimato, A. (1999). Polyphenolic content in five Tuscany cultivars of Olea europaea L. Journal of Agricultural and Food Chemistry, 47, 964-967.

Romani, A., Pinelli, P., Cantini, C., Cimato, A., \& Heimler, D. (2006). Characterization of Violetto di Toscana, a typical Italian variety of artichoke (Cynara scolymus L.). Food Chemistry, 95, 221-225.

Romano, R., Santini, A., Le Grottaglie, L., Manzo, N., Visconti, A., \& Ritieni, A. (2014). Fatty acid composition to differentiate between roasted Arabica and Canephora (Robusta) coffee varieties in mixtures. Journal of Food Composition and Analysis, 35, 1-9.

de la Rosa, L. A., Alvarez-Parrilla, E., \& Gonzalez-Aguilar, G. A. (2010). Fruit and Vegetable Phytochemicals-Chemistry, Nutritional Value, and Stability (1st. ed.). Ames, IA, USA: Wiley-Blackwell.

Rosen, T. (2012). Green tea catechins: Biologic properties, proposed mechanisms of action, and clinical implications. Journal of Drugs in Dermatology, 11, e55-e60.

Rothwell, J. A., Knaze, V., \& Zamora-Ros, R. (2017). Polyphenols: Dietary assessment and role in the prevention of cancers. Current Opinion in Clinical Nutrition \& Metabolic Care, 20(6), 512-521.

Rothwell, J. A., Perez-Jimenez, J., Neveu, V., Medina-Remon, A., M'Hiri, N., Garcia-Lobato, P., ... Scalbert, A. (2013). Phenol-Explorer 3.0: A major update of the Phenol-Explorer database to incorporate data on the effects of food processing on polyphenol content. Database, bat070.

Rothwell, J. A., Urpi-Sarda, M., Boto-Ordonez, M., Knox, C., Llorach, R., Eisner, R., ... Scalbert, A. (2012). Phenol-Explorer 2.0: A major update of the Phenol-Explorer database integrating data on polyphenol metabolism and pharmacokinetics in humans and experimental animals. Database, 2012, bas031.

Sablani, S., Andrews, P., Davies, N., Walters, T., Saez, H., Syamaladevia, R., \& Mohekar, P. (2010). Effect of thermal treatments on phytochemicals in conventionally and organically grown berries. Journal of Science of Food and Agriculture, 90, 769-778.

Sahebkar, A. (2017). Effects of quercetin supplementation on lipid profile: A systematic review and meta-analysis of randomized controlled trials. Critical Reviews in Food Science and Nutrition, 57(4), 666-676.

Sahebkar, A., Serban, C., Ursoniu, S., Wong, N. D., Muntner, P., Graham, I. M., ... Lipid and blood pressure meta-analysis collaboration group (2015). Lack of efficacy of resveratrol on C-reactive protein and selected cardiovascular risk factors-Results from a systematic review and meta analysis of randomized controlled trials. International Journal of Cardiology, 189, 47-55.

Sakakibara, H., Honda, Y., Nakagawa, S., Ashida, H., \& Kanazawa, K. (2003). Simultaneous determination of all polyphenols in vegetables, fruits, and teas. Journal of Agricultural and Food Chemistry, 51(3), 571-581.

Salehi, B., Fokou, P. V. T., Sharifi-Rad, M., Zucca, P., Pezzani, R., Martins, N., \& Sharifi-Rad, J. (2019). The Therapeutic potential of naringenin: A review of clinical trials. Pharmaceuticals (Basel), 12(1), pii: E11). https://doi.org/10.3390/ph12010011

Salehi, B., Venditti, A., Sharifi-Rad, M., Kręgiel, D., Sharifi-Rad, J., Durazzo, A., ... Martins, N. (2019). The therapeutic potential of apigenin. International Journal of Molecular Science, 20(6). pii: E1305). https://doi.org/ 10.3390/ijms20061305

Salehi, B., Zucca, P., Sharifi-Rad, M., Pezzani, R., Rajabi, S., Setzer, W. N., ... Sharifi-Rad, J. (2018). Phytotherapeutics in cancer invasion and metastasis. Phytotherapy Research, 32(8), 1425-1449.

Santana-Gálvez, J., Cisneros-Zevallos, L., \& Jacobo-Velázquez, D. (2017). Chlorogenic acid: Recent advances on its dual role as a food additive and a nutraceutical against metabolic syndrome. Molecules, 22(3), 358.

Santini, A., Cammarata, S. M., Capone, G., lanaro, A., Tenore, G. C., Pani, L., \& Novellino, E. (2018). Nutraceuticals: Opening the debate for a regulatory framework. British Journal of Clinical Pharmacology, 84(4), 659-672.

Santini, A., Ferracane, R., Mikusova, P., Eged, S., Srobaroba, A., Meca, G., ... Ritieni, A. (2011). Influence of different coffee drink preparations on ochratoxin A content and evaluation of the antioxidant activity and caffeine variations. Food Control, 22(8), 1240-1245.

Santini, A., \& Novellino, E. (2014). Nutraceuticals: Beyond the diet before the drugs. Current Bioactive Compounds, 10, 1-12.

Santini, A., \& Novellino, E. (2017a). To nutraceuticals and back: Rethinking a concept. Food, 6(9), 74.

Santini, A., \& Novellino, E. (2017b). Nutraceuticals in hypercholesterolemia: An overview. British J of Pharmacology, 174, 1450-1463.

Santini, A., \& Novellino, E. (2018). Nutraceuticals: Shedding light on the grey area between pharmaceuticals and food. Expert Review of Clinical Pharmacology, 11(6), 545-547.

Santini, A., Novellino, E., Armini, V., \& Ritieni, A. (2013). State of the art of ready-to use therapeutic food: $A$ tool for nutraceuticals addition to foodstuff. Food Chemistry, 140, 843-849.

Santini, A., Tenore, G. C., \& Novellino, E. (2017). Nutraceuticals: A paradigm of proactive medicine. European Journal of Pharmaceutical Sciences, 96, 53-61.

Serban, M. C., Sahebkar, A., Zanchetti, A., Mikhailidis, D. P., Howard, G., Antal, D., ... Lipid and blood pressure meta-analysis collaboration (LBPMC) group (2016). Effects of quercetin on blood pressure: A systematic review and meta-analysis of randomized controlled trials. Journal of the American Heart Association, 5(7). pii: e002713

Serrano, J., Puupponen-Pimiä, R., Dauer, A., Aura, A. M., \& Saura-Calixto, F. (2009). Tannins: Current knowledge of food sources, intake, bioavailability and biological effects. Molecular Nutrition \& Food Res., 53(S2), S310-S329.

Shan, B., Cai, Y. Z., Sun, M., \& Corke, H. (2005). Antioxidant capacity of 26 spice extracts and characterization of their phenolic constituents. Journal of Agricultural and Food Chemistry, 53, 7749-7759.

Sharma, A., Kashyap, D., Sak, K., Tuli, H. S., \& Sharma, A. K. (2018). Therapeutic charm of quercetin and its derivatives: $A$ review of research and patents. Pharmaceutical Patent Analyst, 7(1), 15-32.

Shen, C. Y., Jiang, J. G., Yang, L., Wang, D. W., \& Zhu, W. (2017). Anti-ageing active ingredients from herbs and nutraceuticals used in traditional Chinese medicine: Pharmacological mechanisms and implications for drug discovery. British Journal of Pharmacology, 174, 1395-1425.

Shrikanta, A., Kumar, A., \& Govindaswamy, V. (2015). Resveratrol content and antioxidant properties of underutilized fruits. Journal of Food Science and Technology, 52(1), 383-390.

Siriamornpun, S., \& Kaewseejan, N. (2017). Quality, bioactive compounds and antioxidant capacity of selected climacteric fruits with relation to their maturity. Scientia Horticulturae, 221, 33-42.

Skupien, K., \& Oszmianski, J. (2004). Comparison of six cultivars of strawberries (Fragaria $x$ ananassa Duch.) grown in northwest Poland. European Food Research and Technology, 219, 66-70.

Smeds, A. I., Eklund, P. C., Sjoholm, R. E., Willfor, S. M., Nishibe, S., Deyama, T., \& Holmbom, B. R. (2007). Quantification of a broad spectrum of lignans in cereals, oilseeds, and nuts. Journal of Agricultural and Food Chemistry, 55, 1337-1346

Smeriglio, A., Barreca, D., Bellocco, E., \& Trombetta, D. (2016). Chemistry, pharmacology and health benefits of anthocyanins. Phytotherapy Research, 30, 1265-1286.

Smeriglio, A., Barreca, D., Bellocco, E., \& Trombetta, D. (2017). Proanthocyanidins and hydrolysable tannins: occurrence, dietary intake and pharmacological effects. British Journal of Pharmacology, 174(11), 1244-1262. 
Sohrab, G., Ebrahimof, S., Hosseinpour-Niazi, S., Yuzbashian, E., Mirmiran, P., \& Azizi, F. (2018). Association of dietary intakes of total polyphenol and its subclasses with the risk of metabolic syndrome: Tehran lipid and glucose study. Metabolic Syndrome and Related Disorders, 16(6), 274-281.

Soleimani, V., Sahebkar, A., \& Hosseinzadeh, H. (2018). Turmeric (Curcuma longa) and its major constituent (curcumin) as nontoxic and safe substances: Review. Phytotherapy Research, 32(6), 985-995.

Spencer, J. P. (2010). The impact of fruit flavonoids on memory and cognition. British Journal of Pharmacology, 104(3), S40-S47.

Stuper-Szablewska, K., \& Perkowski, J. (2017). Phenolic acids in cereal grain: Occurrence, biosynthesis, metabolism and role in living organisms. Critical Review of Food Science and Nutrition, 4, 1-12.

Sultana, B., \& Anwar, F. (2008). Flavonols (kaempeferol, quercetin, myricetin) contents of selected fruits, vegetables and medicinal plants. Food Chemistry, 108, 879-884.

Tabeshpour, J., Mehri, S., Shaebani Behbahani, F., \& Hosseinzadeh, H. (2018). Protective effects of Vitis vinifera (grapes) and one of its biologically active constituents, resveratrol, against natural and chemical toxicities: A comprehensive review. Phytotherapy Research, 32(11), 2164-2190.

Tabrizi, R., Tamtaji, O. R., Lankarani, K. B., Akbari, M., Dadgostar, E., Dabbaghmanesh, M. H., ... Asemi, Z. (2018). The effects of resveratrol intake on weight loss: A systematic review and meta-analysis of randomized controlled trials. Critical Review in Food Science and Nutrition, 13, 1-16.

Tapsell, L. C., Neale, E. P., \& Probst, Y. (2019). Dietary patterns and cardiovascular disease: Insights and challenges for considering food groups and nutrient sources. Current Atherosclerosis Report, 21(3), 9.

Tariq, A., Sadia, S., Pan, K., Ullah, I., Mussarat, S., Sun, F., ... Adnan, M. A. (2017). A systematic review on ethnomedicines of anti-cancer plants. Phytotherapy Research, 31(2), 202-264.

Teng, H., \& Chen, L. (2019). Polyphenols and bioavailability: An update. Critical Review in Food Science and Nutrition. https://doi.org/10.1080/ 10408398.2018.1437023

Tomas-Barberan, F. A., Cienfuegos-Jovellanos, E., Marin, A., Muguerza, B., Gil-Izquierdo, A., Cerda, B., ... Espin, J. C. (2007). A new process to develop a cocoa powder with higher flavonoid monomer content and enhanced bioavailability in healthy humans. Journal of Agricultural and Food Chemistry, 55, 3926-3935.

Tresserra-Rimbau, A., Guasch-Ferré, M., Salas-Salvadó, J., Toledo, E., Corella, D., Castañer, O., ... PREDIMED study investigators (2016). Intake of total polyphenols and some classes of polyphenols is inversely associated with diabetes in elderly people at high cardiovascular disease risk. Journal of Nutrition. pii, jn223610

Tresserra-Rimbau, A., Medina-Remón, A., Pérez-Jiménez, J., MartínezGonzález, M. A., Covas, M. I., Corella, D., ... Lamuela-Raventós, R. M. (2013). Dietary intake and major food sources of polyphenols in a Spanish population at high cardiovascular risk: The PREDIMED study. Nutrition Metabolism and Cardiovascular Disease, 23(10), 953-959.

Tresserra-Rimbau, A., Rimm, E. B., Medina-Remón, A., Martínez-González, M. A., de la Torre, R., Corella, D., ... PREDIMED Study Investigators (2014b). Inverse association between habitual polyphenol intake and incidence of cardiovascular events in the PREDIMED study. Nutrition Metabolism and Cardiovascular Diseases, 24(6), 639-647.

Tresserra-Rimbau, A., Rimm, E. B., Medina-Remón, A., Martínez-González, M. A., López-Sabater, M. C., Covas, M. I., ... PREDIMED Study Investigators (2014a). Polyphenol intake and mortality risk: A re-analysis of the PREDIMED trial. BMC Medicine, 12, 77.
Tsuda, T. (2018). Curcumin as a functional food-derived factor: Degradation products, metabolites, bioactivity, and future perspectives. Food \& Function, 9(2), 705-714.

Tungmunnithum, D., Thongboonyou, A., Pholboon, A., \& Yangsabai, A. (2018). Flavonoids and other phenolic compounds from medicinal plants for pharmaceutical and medical aspects: An overview. Medicine, 5(3). pii: E93

Umphress, S. T., Murphy, S. P., Franke, A. A., Custer, L. J., \& Blitz, C. L. (2005). Isoflavone content of foods with soy additives. Journal of Food Composition and Analysis, 18, 533-550.

USDA website. USDA Food Composition Databases. Available online: https://ndb.nal.usda.gov/ndb/ (accessed on 20 May 2019).

Valavanidis, A., Vlachogianni, T., Psomas, A., Zovoili, A., \& Siatis, V. (2009). Polyphenolic profile and antioxidant activity of five apple cultivars grown under organic and conventional agricultural practices. International Journal of Food Science \& Technology, 44, 1167-1175.

Vanguru, M., Merugu, R., Garimella, S., \& Laxminarayana, E. (2018). A review on the synthetic methodologies of chromones. Asian Journal of Pharmaceutical and Clinical Research, 11(12), 9-16.

Venkata Sairam, K., Gurupadayya, B. M., Chandan, R. S., Nagesha, D. K., \& Vishwanathan, B. (2016). A review on chemical profile of coumarins and their therapeutic role in the treatment of cancer. Current Drug Delivery, 13(2), 186-201.

Vermerris, W., \& Nicholson, R. (2008). Phenolic compound biochemistry. In Families of phenolic compounds and means of classification (pp. 1-34). Dordrecht, The Netherlands: Springer.

Wallace, T. C., Slavin, M., \& Frankenfeld, C. L. (2016). Systematic review of anthocyanins and markers of cardiovascular disease. Nutrients, 8. pii: E32

Weber, F., \& Larsen, L. R. (2017). Influence of fruit juice processing on anthocyanin stability. Food Research International, 100, 354-365.

Wezeman, T., Brase, S., \& Masters, K. S. (2015). Xanthone dimers: A compound family which is both common and privileged. Natural Product Report, 32, 6-28.

Wijaya, G. Y., \& Mares, D. J. (2012). Apigenin di-C-glycosides (ACG) content and composition in grains of bread wheat (Triticum aestivum) and related species. Journal of Cereal Science, 56, 260-267.

Wishart, D. S., Feunang, Y. D., Marcu, A., Guo, A. C., Liang, K., VázquezFresno, R., ... Scalbert, A. (2018). HMDB 4.0-The Human Metabolome Database for 2018. Nucleic Acids Research, 46, D608-D617.

Witkowska, A. M., Waśkiewicz, A., Zujko, M. E., Szcześniewska, D., Stepaniak, U., Pająk, A., \& Drygas, W. (2018). Are total and individual dietary lignans related to cardiovascular disease and its risk factors in postmenopausal women? A nationwide study. Nutrients, 10(7), 865 .

Wu, X., Beecher, G. R., Holden, J. M., Haytowitz, D. B., Gebhardt, S. E., \& Prior, R. L. (2006). Concentrations of anthocyanins in common foods in the United States and estimation of normal consumption. Journal of Agricultural and Food Chemistry, 54, 4069-4075.

Xiao, Y., Zhang, S., Tong, H., \& Shi, S. (2018). Comprehensive evaluation of the role of soy and isoflavone supplementation in humans and animals over the past two decades. Phytotherapy Research, 32(3), 384-394.

Xing, L., Zhang, H., Qi, R., Tsao, R., \& Mine, Y. (2019). Recent advances in the understanding of the health benefits and molecular mechanisms associated with green tea polyphenols. Journal of Agricultural and Food Chemistry, 67(4), 1029-1043.

Yasunaka, K., Abe, F., Nagayama, A., Okabe, H., Lozada-Perez, L., LopezVillafranco, E., ... Reyes-Chilpa, R. (2005). Antibacterial activity of crude 
extracts from Mexican medicinal plants and purified coumarins and xanthones. Journal of Ethnopharmacology, 97, 293-299.

Yilmaz, P. K., \& Kolak, U. (2017). SPE-HPLC determination of chlorogenic and phenolic acids in coffee. Journal of Chromatographic Science, 55, 712-718.

Yixiang, W., Qing, L., Qian, W., Junhong, L., Lili, L., Xiaohui, C., \& Kaishun, B. (2011). Simultaneous determination of seven bioactive components in Oolong Tea Camellia sinensis: Quality control by chemical composition and HPLC fingerprints. Journal of Agricultural and Food Chemistry, 60(1), 256-260.

Zaheer, K., \& Humayoun Akhtar, M. (2017). An updated review of dietary isoflavones: Nutrition, processing, bioavailability and impacts on human health. Critical Reviews in Food Science and Nutrition, 57, 1280-1293. https://doi.org/10.1080/10408398.2014.989958

Zeng, W., Jin, L., Zhang, F., Zhang, C., \& Liang, W. (2018). Naringenin as a potential immunomodulator in therapeutics. Pharmacology Research, 135,122-126.

Zhang, H., Tang, B., \& Row, K. (2014). Extraction of catechin compounds from green tea with a new green solvent. Chemical Research in Chinese Universities, 30, 37-41.

Zhang, H., \& Tsao, R. (2016). Dietary polyphenols, oxidative stress and antioxidant and anti-inflammatory effects. Current Opinion in Food Science, 8, 33-42.
Zhang, J., Li, L., Kim, S. H., Hagerman, A. E., \& Lü, J. (2009). Anti-cancer, anti-diabetic and other pharmacologic and biological activities of penta-galloyl-glucose. Pharmaceutical Research, 26(9), 2066-2080.

Zhang, M., Zhang, X., Ho, C. T., \& Huang, Q. (2019). Chemistry and health effect of tea polyphenol (-)-Epigallocatechin 3- O-(3- O-Methyl) gallate. Journal of Agricultural and Food Chemistry, 67, 5374-5378.

Zhao, C. L., Yu, Y. Q., Chen, Z. J., Wen, G. S., Wei, F. G., Zheng, Q., ... Xiao, X. L. (2017). Stability-increasing effects of anthocyanin glycosyl acylation. Food Chemistry, 214, 119-128.

Zheng, W., \& Wang, S. Y. (2001). Antioxidant activity and phenolic compounds in selected herbs. Journal of Agricultural and Food Chemistry, 49(11), 5165-5170.

Zhou, Y., Zheng, J., Li, Y., Xu, D. P., Li, S., Chen, Y. M., \& Li, H. B. (2016). Natural polyphenols for prevention and treatment of cancer. Nutrients, 8(8). pii: E515

How to cite this article: Durazzo A, Lucarini M, Souto EB, et al. Polyphenols: A concise overview on the chemistry, occurrence, and human health. Phytotherapy Research. 2019;33:2221-2243. https://doi.org/10.1002/ptr.6419 